Portland State University

PDXScholar

Engineering and Technology Management

Faculty Publications and Presentations

8-1-2015

\title{
Explaining Health Technology Adoption: Past, Present, Future
}

Noshad Rahimi

Portland State University

Antonie J. Jetter

Portland State University, ajetter@pdx.edu

Follow this and additional works at: https://pdxscholar.library.pdx.edu/etm_fac

Part of the Operations Research, Systems Engineering and Industrial Engineering Commons Let us know how access to this document benefits you.

\section{Citation Details}

Rahimi, N., \& Jetter, A. (2015). Explaining health technology adoption: Past, present, future. In 2015 Portland International Conference on Management of Engineering and Technology (PICMET) (pp. 2465-2495). IEEE.

This Article is brought to you for free and open access. It has been accepted for inclusion in Engineering and Technology Management Faculty Publications and Presentations by an authorized administrator of PDXScholar. Please contact us if we can make this document more accessible: pdxscholar@pdx.edu. 


\title{
Explaining Health Technology Adoption: Past, Present, Future
}

\author{
Noshad Rahimi, Antonie Jetter \\ Dept. of Engineering and Technology Management, Portland State University, Portland, OR - USA
}

\begin{abstract}
One of the most pressing challenges of healthcare innovation today is the lack of technology adoption. Research that improves our ability to understand, predict, and advance technology adoption in health care needs to be based on welltested theories. With the interest to conduct high quality research in health technology adoption in future, this study reviews the theories used in this context to either identify the superior theory(ies) and or discover the issues that need resolution for improving future HTA researches. To do that, the most popular [1][2] social cognitive theories conceived over the past four decades are reviewed analytically from the perspective of their capacity to explain, predict and intervene in health technology acceptance, adoption and adherence. While all these theories are instrumental in conducting adoption studies, and some like UTAUT (Unified Theory of Acceptance and Use of Technology) are better than others at it, there is no perfect theory to study HTA. Literature repeatedly suggests that while utilizing general theories that have successfully passed the test of time could serve as a strong foundation, there is a compelling need for new and more empirical theories. There is a need for health researchers to expedite theoretical evolution by conducting comprehensive observation and rigorous evaluation to 1) manipulate and expand existing theories and or 2) create new theories that better address the specific needs and challenges of health technology application to enhance the utility and better reflect empirical findings.

The structure of this paper is as follows. After summarizing the specifics of health technology innovations, the primary challenges in its acceptance are categorized. From there the body of this paper is dedicated to the review of most popular social cognitive theories, as depicted in Figure 1, from: 1) general human behavior repeatedly applied in healthcare studies and rooted HTA researches, and 2) theories dedicated to the study of technology acceptance behavior and applied as the prominent theories in studying HTA. Each theory is reviewed, followed by examples of its applications especially in modeling health technology adoption (HTA) behavior. Each theory is then evaluated based on the salient factors involved in the study of technology innovation in healthcare space in addition to the classical influencing concepts in technology adoption behavior. In the discussion section, these theories are compared and the applications studied are synthesized in the attempt to identify some of the best theories and state of the art practices used in the study of HTA. The conclusion section summarizes the findings of the literature and recommends best approaches for conducting empirical studies and planning effective processes that stimulate theoretical evolution in HTA and facilitate enhancement of acceptance of health technology innovations.
\end{abstract}

Getting a new idea adopted, even when it has obvious advantages, is often very difficult." Everett Rogers, Diffusion of Innovation

\section{HEALTH TECHNOLOGY ACCEPTANCE AND CHALLENGES}

At the top of the government priority list is the alarming annual rate of $7 \%$ increase in healthcare costs which if not reduced will bankrupt Medicare in nine years and increase the nation's overall annual health care spending to $\$ 4$ trillion in 10 years [3]. Technological innovations have not only saved costs in offering more effective solutions, but also been able to reduce errors wherever applied and can promise crucial efficiency particularly in healthcare. Additionally, the advancement of broadband networking of technology can address the pressing fragmentation issues of care delivery. The benefits of technology in healthcare are numerous. It is also important to note that not all technological innovations in healthcare have been cost effective or have made significant differences in improving the quality of care; and there are a lot of experimental innovations that are yet to prove their performance. However, the goal of this paper is to analytically review the literature on the adoption study of the technologies that have already proven to provide superior care, reduce error and save cost. One category of these technologies being particularly focused on here is Remote Health Monitoring Technology (RHMT). RHMT can improve the health of elderly and their caregivers by providing the infrastructure for independent living, while reducing the burden of care giving. RHMT can provide solutions through three pathways: (1) better management of chronic conditions resulting in lower needs for care; (2) improved assessment of care needs in emergency (e.g. falls) and in everyday situations (e.g. subtle cognitive decline) leading to more targeted provision of care, and (3) reduced impact on caregiver schedules by enabling remote check-ins, visits, and data exchange with health care providers and by reducing the occurrence of crisis situations[4].

The adoption of interoperable Electronic Medical Record could provide efficiency and safety savings of \$142-\$371 billion and productivity gain of $\$ 346-\$ 813$ billion in US alone [5]. However, these benefits have not yet been realized due to the lack of user adoption of the technology in healthcare environments [6] For example, one third of wearable device customers have abandoned their devices within six months and half of activity trackers are becoming unused [7]. Long-term adoption is the key to the delivery of the benefits promised by technology and yet it's the biggest challenge health innovation is facing today [8]. Literature suggests that without careful investigation into what it takes for adoption in the complex widespread space of healthcare, the huge investment in health technology is wasted [9]. This is why technology adoption is the top criteria in the Health 
Information Technology for Economic and Clinical Health Act (HITECH Act) by US Department of Health and Human Services, under which $\$ 25.9$ billion is allocated for promoting and expanding the adoption of health information technology [10]. Despite much ongoing research and investment in promoting technology adoption in healthcare domain, lack of adoption is still one of the top issues healthcare is facing today [9], [11]. The investigation into the root cause of the challenges in promoting HTA, necessitates understating of technology adoption in health. Only through this understanding one can identify the gap to achieve better acceptance of innovation into the healthcare domain. The recognition of major influencing factors in one's decision to accept a technology relies on researches that are guided by appropriate theories that can lead to better intervention plans. This report attempts to achieve this objective by reviewing the prominent social cognitive theories and their applications for evaluation of their fitness for HTA studies. The implications drawn can shed light to future direction to enhance acceptance and adoption of innovations in healthcare domain.

To clarify the meaning of recurring concepts in this paper, it's worth noting some of the keywords such as adoption, acceptance and diffusion. As defined in the encyclopedia of information science and technology, adoption is a step toward diffusion where user (individual or organization) decides to select to use a technology [12]. Adoption of New Technology is the choice to acquire and use a new invention or innovation [13]. Hall and Khan posit that (like most of other decisions) the decision to adopt 1) involves a classical cost benefit analysis and 2) there is an option to delay the adoption given the uncertainty to adopt. Throughout the existing literature and therefore this review, the terms adoption and acceptance are used synonymously. While these terms are not identical in their English definition, in the context of technology adoption, they are used interchangeably.

Diffusion similar to its definition (the spread of cultural elements from one area or group of people to others by contact [14] involves time variable and multiple player/groups. Technology diffusion similarly applies to the adoption of technology by group(s) of users and often throughout time [15]. As detailed later (section 3.3. Innovation Diffusion Theory (IDT)) the term diffusion of technology or innovation as popularized by Rogers [16] is generally referred to as the adoption of technology/innovation across different segments of the market (from innovators and early adoptions to early and late majority to laggards [16]). Some refer to technology diffusion when they are highlighting the process of technology adoption over time [17]. Overall, the significant theme observed is that the use of term diffusion refers to the long-term adoption [18], [19].

When it comes to the two terms of "adoption" and "acceptance", they are indistinguishable in the context of technology behavior. While not identical in their English definitions (adoption: the act or process of beginning to use something new or different, or: the act or process of giving official acceptance or approval to something [20]; acceptance: the act of accepting something or someone [21]) in the context of technology usage, have been used interchangeably and synonymously [22], [23] [24]-[28]. For example, Agarwal \& Prasad in their highly cited study in the domain of information technology [29] indistinguishably use these terms as state: "Why do some individuals readily adopt new information technologies while others reject them? This problem, variously labeled information systems implementation, technology adoption, and technology acceptance, has persisted in the information systems literature for several decades." [29]. Needless to emphasize that, the term "decision making" is a step in the process of adoption/acceptance when the technology usage is decided on [23][30], [31].

Decades of research and practice into the field of behavior has highlighted the importance of understanding and following theoretical models to implement more effective health behavior change interventions [32]. Glanz et al., the authors of a highly cited book: "Health behavior and health education: theory, research, and practice", state "the best theory is informed by practice; the best practice should be grounded in theory [33]. Fishbein specifically emphasize on this by claiming that whoever understands the factors influencing whether a given piece of information will be accepted or rejected, will make a real contribution to improving public health [34].

From overeating, smoking, to opting out of personal health record software, or not using a health remote monitoring system, human behavior is the key determinant in one's health and medical condition. This importance has brought human behavior to the center of health research for more effective intervention plans and to alleviate their detrimental impacts in the attempt to enhance quality of life. If best practice should be grounded in theory [33], to conduct a solid empirical research of technology innovation in healthcare, one should review the well-tested popular human behavior theories applied, validated and or extended to health technology studies. This would be the first and one of the most important steps for better understanding and predicting as well as planning effective intervention in such applications.

As Fishbein claims, the more we know about the drivers of any given behavior, the more capable we are in designing and implementing effective intervention in that behavior [35]. The review of health behavior intervention studies make it evident that researching into the salient factors influencing the health behavior in general and technology innovation in healthcare in particular can lead into creation of effective adoption planning and processes. Human behavior prediction and planning for intervention are very complex; however as exemplified throughout this paper, literature repeatedly provides evidences of successful innovation adoption studies when they are based on proven human behavior theories, particularly those focused on technology adoption. These evidences make reviewing human behavior theories an 
important step toward conducting any technology adoption in healthcare.

According to Kerlinger and Lee: "a theory is a set of interrelated (concepts), definitions, and propositions that present a systematic view of phenomena by specifying relations among variables, with the purpose of explaining and predicting phenomena." [33] And Hochbaum et al. defines Health Behavior Theory as: "tools to help health educators better understand what influences health-relevant individual, group, and institutional behaviors and to thereupon plan effective interventions directed at healthbeneficial results." [36]

Human Behavior Theories (HBT) reviewed here, as depicted in Figure 1, is based on continuum model as opposed to the stage model, which identifies the process of change through the stages, for advancing through the health behavior intervention process. Continuum models are the focus of this paper, as they are designed for studying the determinant factors and their causal relationship resulting in a health behavior. DiClemente et al. suggest that effective health behavior theory should lay the ground work by providing a framework to facilitate identification and selection of key determinants believed to drive the health behavior and to enable effective applied research, intervention development, implementation and evaluation [37]. This highlights the importance of finding the model that is best suited based on the health behavior being targeted.

Health related behaviors are more than often charged by a range of emotional factors from fear and threat to mood and worries. Other determinants include personal, moral and social norms such as sense of identity, responsibility and culture. Failure to include these factors leads to poor predictability [36] If this is not challenging enough, technology solutions add extra layers of complexity to this messy paradigm. Technological innovations often require learning and changes to status quo mandating modification to the processes people are used to and hence comfortable with.
All these inconveniences result in a natural resistance to technology acceptance in this space. Beyond the general influencing factors, some of the salient factors that are particularly significant in accepting technology in healthcare are categorized below.

\section{A. Emotional influences}

Health decisions are often emotionally charged and more than often involves compulsion and other irrational and noncognitive factors. Investigations into the human decisionmaking have consistently found both anticipated and anticipatory emotions influential [38]-[40]. Many researchers have found emotion as markers, mediators, and moderators of consumer behavior. The influence of emotion on cognitive processes, including volitions, decision and goal-orientation are well recognized [41]-[43]. Many studies have identified emotion to be a primal factor in the process of technology acceptance [44]-[46]. The importance of emotions is even more significant in the health decisions and in particular in the context of health technology adoption among elderly [47], [48]. Some group of emotions such as computer anxiety, (the uneasiness when facing the decision of using computer [49]) negatively affect the health technology usage [49], [50]; and some other groups of emotion like playfulness (the joy associated with the spontaneous play and interaction with computer [51]) promote the desire to accept health technology [52]. Since emotion guides behavior and influences both the processing and judgment of information [42], [43], [53], which is even more important in the context of HTA, it's key that any model utilized for the study of health technology adoption must pay attention to this concept. Therefore to successfully identify the key factors and capture the cognitive process of elderly during the process of technology acceptance/rejection, the theory being utilized need to consider the emotional factors and their influence on behavior.

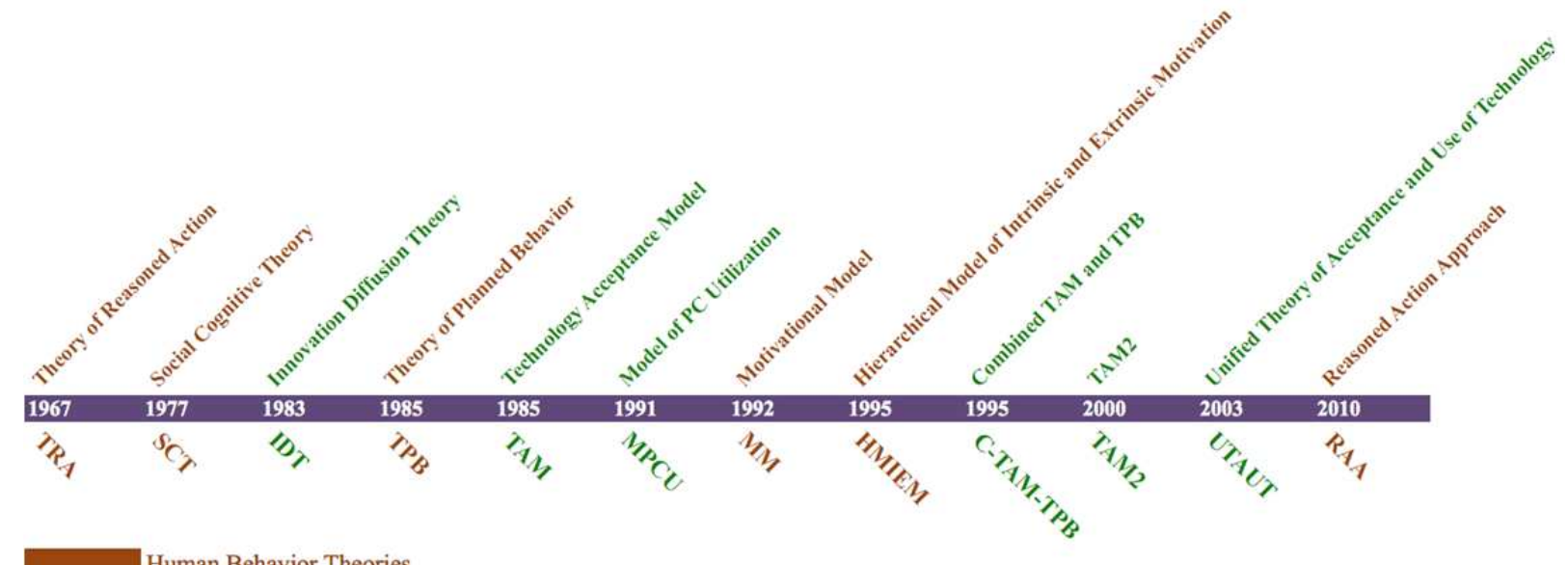

Human Behavior Theories Technology Adoption Theories

Figure 1 - Theories Timeline 


\section{Proceedings of PICMET '15: Management of the Technology Age}

\section{B. Value sensitivity}

Despite the prevalence of economic measure of cost benefit analysis in almost all human decision making to evaluate whether the benefits outweigh the costs, more than often healthcare related decisions have do not fit the traditional cost benefit analysis [54]. In an earlier study for assessing technology alternatives for orthopedic surgery post discharge care, without any surprize, expert judgment consistently identified quality related criteria vital for any alternatives to be considered. In fact reliability, safety, data integrity and security were all measured higher than any cost factor in the model [55]. This can explain why there are hardly any evidence in the literature of health system related cost effectiveness threshold measures [56]. For a model to realistically unpack human decision it should have the capacity to capture these value sensitiveness.

\section{Demographic sensitivity}

Diversity of the users characteristics, knowledge level, cultural differences, and in particular gender and age are major determinants in the health adoption decisions. Literature provides much evidence to the significance of the role of demographics in technology adoption in healthcare. With the surge of innovations and prevalence of technology adoption among younger generations, HTA is lagging behind among the elderly despite their known health benefits [57], [58]. A study of IT adoption by Wild et. al [59] emphasizes that adoption is more challenging in elderly as cognitive decline deepens lack of confidence and increases anxiety regarding computer use [59]. Regarding gender, several studies show [60]-[62] that men approach technology in an outcome-oriented fashion: a positive attitude towards the capabilities of the technology explains more than half of the variance in the intention to use. For women, social norms and perceived behavior control (voluntarism) are more salient drivers of adoption and the attitude, usage barriers, and usage motives together explain only half of the intention to use. A study by Wilkowska et. al. [61] on the acceptance of medical assistive technologies also revealed gender differences: women generally had a less positive attitude towards the technology, were slightly more concerned about privacy and the stigma of having to use assistive technologies, and faced greater challenges in technology use than men, even though their overall technology attitudes were positive and usage intentions were high. Thus technology adoption unfolds differently for men and women: perceived usefulness of the technology is decisive for men, but women consider a multitude of other practical and social factors. These findings echo results from research on gender differences in financial decision making [63], retirement choices [64], and problem solving in hospitals [65]. Gender and age-specific concerns shape how elderly women adopt technology. Therefore, it's vital to consider demographic characteristics, as determinants in mapping the cognitive process of HTA and the facilitating model should be sensitive to these factors.
The subject of adoption among elderly is particularly important in healthcare technology studies. The global aging phenomena and the disproportionate and staggering cost of elderly healthcare have been putting unprecedented pressure on the economy and priorities of the global society. This highlights the importance of theories that account for these differentiating factors.

\section{Volitional and self-efficacy}

Behavioral control or self-efficacy and voluntariness play important roles in human behavior [66][67]. Their role is particularly significant in health decisions [68] and consumer spaces and or environments where the adoption is not enforced [69]. Self-efficacy is particularly determinant in the elderly HTA [59] Many studies emphasize on the importance of taking self-efficacy into consideration where HTA is being studied [70]. Hence unless a health adoption decision model takes volition into consideration, it can't realistically capture the key determinants involved in acceptance of health technology.

\section{E. Time sensitivity}

Initial adoption does not necessarily mean long-term usage and the true benefits of health technology innovations are generally realized when they are used over a long period of time. There are much evidence in the literature that short term adoption does not guarantee long-term adoption [7] and the factors that influence initial health innovation usage are different from the ones lead to their long-term diffusion[8], [71], [72] and in particular for elderly [58]. A study of location tracking usage among elderly by Thomas et al. discovered that while perceived usefulness, privacy and visibility predicted the usage, perceived risk was only the indicator of usage after a period of time [58]. Therefore unless modeling human cognitive processes involved in health technology adoption has the capability to differentiate between these two different behaviors (short-term vs. longterm adoption), the true mental model describing long-term adoption process is not unpacked.

\section{F. Practicality}

The capacity of the theory to be appropriately applied to the complex empirical studies of technology adoption in healthcare domain is the key requirement for opening the black box of HTA. As widely described by Kerlinger and Lee, 'a theory is a set of interrelated (concepts), definitions, and propositions that present a systematic view of phenomena by specifying relations among variables, with the purpose of explaining and predicting phenomena [73]. Needless to say that for a theory to successfully explain and predict the phenomena, it should contain the appropriate and significant concepts for those phenomena. In the context of HTA and for the purpose of this paper's criteria to find most promising theories in the domain of healthcare, each theory is practicality assessed based on its granularity and awareness 
of the key determining factors in the study of health technology adoption. For a theory to successfully facilitate explaining, predicting and or intervening the adoption in such a paradoxical, emotional, irrational, 'demographics, value and time sensitive' application of technology, it should inherently take these key determinants into account. These sets of expectations become the criteria in which this paper critically evaluates the theories identified, for their fitness in conducting HTA research.

\section{HUMAN BEHAVIOR THEORIES}

This section of the paper reviews the top five theories that have been both utilized in explaining and promoting, among others, innovation adoption in general and HTA in particular, and have provided foundation to the specific theories later designed for studying technology adoption. These theories are some of the most important and influential modern principles that have provided insight to human behavior and the cognitive process involved in decision making. Among other applications, with the prevalence of information technology across the industries, these theories have been extensively utilized to explain, predict and particularly promote technology adoption since the last two decades of the previous millennium. This report has identified: Social Cognitive Theory (SCT), Theory of Reasoned Action (TRA), Theory of Planned Behavior (TPB), Reasoned Action Approach (RAA), Hierarchical Model of Intrinsic and Extrinsic Motivation (HMIEM) and Motivational Model (MM), as the most influential and applied theories since they have been utilized for studying HTA and contributed to the creation of technology adoption specific theories reviewed in the next section.

\section{A. Social Cognitive Theory (SCT) \\ 1) Overview}

Theorized by the Canadian Psychologist Albert Bandura in 1986, and rooted from the Social Learning Theory, Social Cognitive Theory [74] is one of the most researched theories and has been applied to many fields including the study of technology adoption and HTA [75], [76]. Social Cognitive Theory finds its root in social learning theory by Miller and Dollard in 1941 [77]. Psychological theories in discovering and explaining why people behave as they do, like in other fields, have advanced over years. Until recent decades, it was believed that human is unconsciously and solely influenced by the internal forces in the form of impulses, needs or drivers. Later studies into human behavior uncovered the importance of external stimulus and its effects on evoking behavior and the environmental consequences that alter it [78]. These findings led to the more recent theories highlighting the importance of environmental forces in driving behavior [79]. However those social and behavioral theories' main concentration had been on the influence of social and environmental factors on the personal or group behavior. SCT contribution is in its claim that human behavior is the result of dynamic and mutual influence of the three factors of personal, social and behavioral on each other [68].

SCT in its core, tries to describe how one controls behavior through self-regulation and reinforcement toward achieving goal. Below is a description of SCT main constructs [80].

\section{2) Concepts}

\section{Reciprocal Determination}

As depicted below, social cognitive theory's main emphasis is on the concept that the three primal factors of personal, environmental and behavior have reciprocal relationship and mutual effects on each other. As mentioned above, SCT highlights the dynamic relations of these factors and their interplaying influence on each other as opposed to the human behavior being the unidirectional product of the external social stimuli. It explains the influence of one's vision on its surrounding society. Many efforts in improving public health, such as Patient Protection and Affordable Care Act, showcase this reciprocal influence as they highlight the attempts of the society to change the environmental factors with the intention to promote higher quality of life for everyone [35].

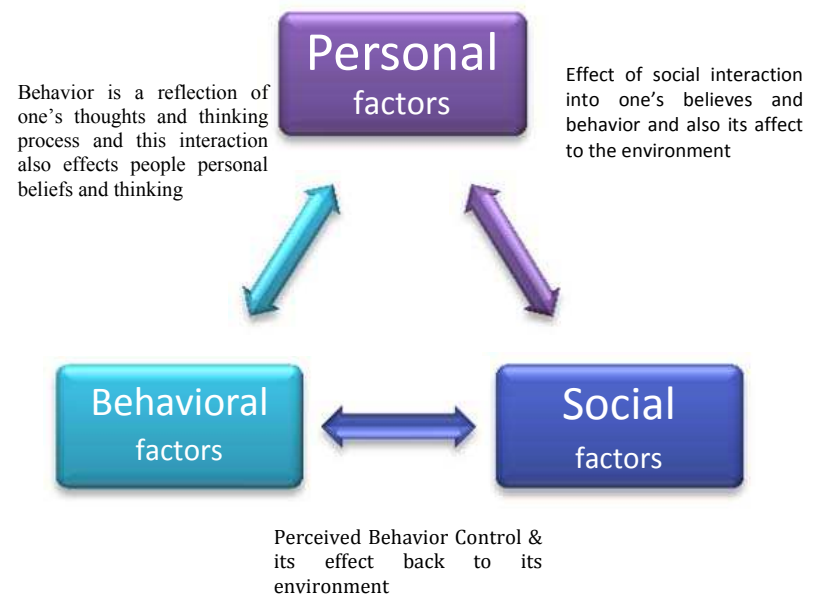

Figure 2 - Social Cognitive Theory[74]

\section{Observation Learning}

In essence, SCT is a social learning theory with the claim that people learn by observing others. The environment (social factors), behavior and cognition (personal factors) all influence each other and actively participate in the process of learning. For this learning or modeling behavior to happen, one should observe the successful manifestation of the behavior from others [80].

\section{Self-efficacy}

Arguably, Self-efficacy is the most important concept of Social Cognitive Theory that was added when the theory evolved from social learning [80]. It reflects one's belief and 
confidence in the ability to successfully conduct a behavior. Many personal and environmental factors influence selfefficacy [81]. Self-efficacy is a major determinant in how one behave, conduct task and take on challenges [81]. The SCT posits that social learning will likely happen if the observer senses a close identification with the model (i.e. if he can do it I can too) and that the observer has a strong self-efficacy (I know I can do it) [82]. The concept of Self-efficacy has been applied in many healthcare behavior predictions. For example, a research group in the university of Illinois has designed an Exercise Self-Efficacy Scale that evaluates individuals' perception in their ability to commit to a regular exercise routine [83]. While strong self-efficacy can promote taking action, lack of which can inhibit initiation and reduce the motivation to act. This is extended to all aspects of human's actions including technology adoption [84] and HTA [85].

\section{Performance Expectations}

One of the key determining factors in human behavior that is highlighted in SCT is "outcome expectation". Outcome expectation is what the individual perceives as the potential outcomes of a behavior and their values; and it's theorized to drive the behavior. SCT emphasizes that these expectations are subjective and not just based on objective facts. SCT also stresses on the importance of this vision into the future and its effect of making human capable of forgoing immediate benefit to reach a more long-term goal.

Based on SCT, anticipation controls human motivation and action. This forethought breaks down to three components: For example: Jane has a chronic disease and contemplating whether to install a remote health monitoring system.

a) Situation outcome anticipation: The effect of the environment.

(Management of my chronic condition is becoming too challenging and frequent doctor visit is becoming too hard)

b) Action outcome anticipation: The effect of the person's action.

(If I use a remote health monitoring system, I can better manage my health condition independently)

c) Self-efficacy:

(I am capable of using and handling the technology) [86].

\section{Behavioral Capability}

Behavioral capability or the concept of agentic refers to the basic human capacity to control own life and over nature. SCT posits that human is a self-regulated proactive being and not just formed by the environmental factors or influenced by impulses. One is capable of making individual choices based on own knowledge and skills, regardless of the external stimulus. For this the person should know what to do and how to do it. The experience not only provides the person with a learning opportunity, it also influences the surrounding environment [82]. In the social context, personal agency occurs in relations to a series of social drivers. In this relation, individuals are both the producers and the products of social system. Bandura identifies three modes of agency: 1) personal agency (act independently), 2) proxy agency (others acting on behalf of or for one's interest, e.g. lawyer), 3) collective agency (conducted via a social and coordinated endeavor, e.g. social movements) [87].

\section{Reinforcements}

In SCT, reinforcement, or the internal and external consequences of one's behavior has a direct relation with the probability of person's sustaining or ceasing that behavior. The consequence can be positive or negative and can be internal or from external environment. Regardless of its source or value, reinforcement both drives the initiation as well as adherence to conducting a behavior. It is one of the driving forces produced by the interrelationship of the behavioral and environmental factors [88]. For example, if Jane observes that her friend has benefited from the remote health monitoring system, this observation can motivate her to also give the remote health monitoring system a try. And if her efforts are fruitful in that she actually receives benefits from her initial use of the system, it is more likely that she will continue to utilize it. This reinforcement is different from imitation as there are various behaviors being adopted.

\section{3) Application and Extension}

SCT is one of the most popular modern theories to study human behavior. A Google Scholar search on "Social Cognitive Theory Health" brings up more than 2.7 million results including many books on Health promotion [88] and predicting health behavior [67] and or health education [34], [81] using SCT. The role of Self-efficacy has been studied in many fields including health promoting research [89], technology adoption [84] and HTA [85]. These studies range from understanding to predicting and or changing those behavior. SCT concepts have also been used as a scale to measure and predict performance. For example, a research group in the university of Illinois has designed an Exercise Self-Efficacy Scale that evaluates individuals' perception in their ability to commit to a regular exercise routine [83].

Miller et al. applied SCT to health protective behavior, advocating for a Cognitive-Social Health Information Processing model (C-SHIP). The model facilitate creation and maintenance of health protective behavior by studying the individual's encodings and construal's (how one comprehend, perceive and interpret others' behavior), expectancies, affects, goals and values, self-regulatory competencies, and their interactions with each other and the health-relevant information in the course of cognitiveaffective processing [89].

Agarwal et al. research to identify factors affecting patient use of personal health records (PHR) and secure messaging, utilized SCT. They theorized and tested two categories of personal and environmental factors that believed to be influential in patients' intention to use PHR and hence 
concluded on the importance of communication tactics and technology characteristics and implications that helped in improving the adoption of PHR [85]. Tufano and Karras study, to find and suggest ways to leverage the adoption of mobile eHealth for obesity, also utilized design principles drived from the study of SCT [90].

To better inform the studies, SCT has also been used in combination with more specific technology adoption theories. For example, to discover women's preferred features for mobile physical activity application design, Ehlers and Huberty utilized theory-based features by designing surveys based on principles of both SCT and UTAUT (described later) [76].

Many social marketing models, lessons and strategies have been obtained and implemented using SCT, which is mainly implemented through tailored informational and or marketing intervention [91]. Bandura in his examination of health promotion and disease prevention from the perspective of social cognitive theory [92], posits that SCT addresses both the health socio structural determinants and personal determinants. He highlights the evolution of shifting from scaring people to rewarding them into health and emphasize on the significance of reciprocal interplay between selfregulatory and environmental drivers of health behavior. This highlights the need for changing social practice systems that can fundamentally promote health (such as technological solutions) as opposed to focusing on changing individual's behavior alone [92].

\section{4) Evaluation}

Social Cognitive theory is a strong theory in understanding and intervening in human behavior. It's known as one of the most influential theories of human behavior [74] SCT's Self-efficacy is its greatest contribution in theorizing human behavior; it has influenced technology adoption theories like TPB. As Wood and Bandura postulate, the benefit of this triadic theory is in its dynamic changing interplay of personal and environmental factors in a reciprocal causal relationship. This creates a conceptual framework that clearly maps the psychological mechanism where social factors links to (and from) cognition and behavior [92]. They however argue that these cognitive approaches to decision making are limited in the sense that they often dismiss the effect of factors such as motivation, affect and other personal constructs on the individual's information acquisition, evaluation and choice [93].

Based on objective of this report to evaluate the existing theories in regards to their fitness for studying health technology adoption, SCT and its utility for such studies need to be assessed based on the applying salient criteria identified earlier and below.

Emotional influences: As claimed by Bandura himself, affect is dismissed by SCT approach to decision making [92]. While the emphasis on the reciprocal relationship between cognition and environmental and behavioral factors unpack many influential concepts in human behavior, the emotional irrationality and impulsivity is overlooked and hence the theory is not capable of explaining the emotional decisions often made in healthcare space.

Demographic sensitivity: SCT ignores the role of demographic characteristics in human decision-making. Based on SCT one's behavior is heavily influenced by learning from the environment and fails to consider other key determinants such as gender and age, which as cited earlier are key in the adoption of health technologies.

Volitional and self-efficacy: At the heart of SCT, is the primal pillar of volitional power and its spectacular influence on behavior. This provides an advantageous mechanism to model the behavioral controls needed to accept the technology particularly in the health technology choices that are voluntary.

Time sensitivity: The fact that SCT models the dynamic interchanging relation of three categories of person, environment and behavior factors in a triadic dynamic interplay, affords it the potential to capture the effect of time and therefore the initial behavior versus the long-term adoption [80].

Practicality: While general theories like SCT are broadly applied and can conceptually explain behavior, they lack the granularity required to determine the extent of influence of one factor on another and hence, unless fully decomposed, they are not ideal for empirical research in health technology acceptance. The fact that SCT's theorization of decisionmaking is too broad and missing the salient factors influencing one's health technology adoption decision, makes SCT unfit for conducting empirical researches in HTA. This is evident by a study of personal health record adoption, where Agarwal et al. had to add individual and environmental factors from literature to the general SCT, for their PHR adoption model [85].

\section{B. Theory of Reasoned Action (TRA) \\ 1) Overview}

Rooted in social psychology, Theory of Reasoned Action (TRA) models the prediction of behavior. Fishbein originated TRA in 1967 [94] and further developed it with Ajzen in 1975 [95]. TRA intended to address the shortcoming of earlier models that couldn't clearly correlate attitude to behavior. TRA posits that human attitude (A) is naturally drived from beliefs that in turn influence the corresponding behavior intention (BI). In addition to one's attitude, the perceived beliefs and expectations of the significant surrounding people (SN) and the desire to comply with those, also drives the behavioral intention (BI). The following formula and figure exhibit how Behavior intention becomes a function of attitude and subjective norms, as further described in the following section [95].

$$
\mathbf{B I}=\mathbf{A}+\mathbf{S N}=\Sigma \mathbf{b}_{\mathbf{i}} \cdot \mathbf{e}_{\mathbf{i}}+\boldsymbol{\Sigma} \mathbf{n b}_{\mathbf{i}} \cdot \mathbf{m} \mathbf{c}_{\mathbf{i}}
$$




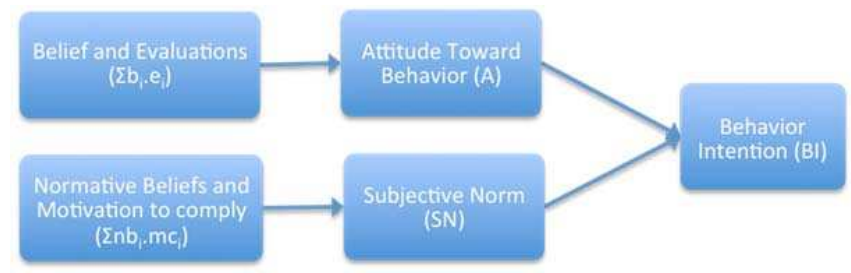

Figure 3 - Theory of Reasoned Action (TRA) [95].

In the above formula, BI (Behavior Intention) not only represents the human behavior intention, it also captures the strength and likelihood that it affects the performance of the considered behavior.

\section{2) Concepts}

\section{Attitude Toward Behavior}

A (Attitude toward behavior) represents the collection of one's all positive and negative beliefs about their consequences, multiplied by their subjective evaluations about a considered behavior:

$$
A=\Sigma b_{\mathbf{i}} \cdot \mathbf{e}_{\mathbf{i}}
$$

Here, $b_{i}$ represents the individual's perceived belief of the consequence of performing the behavior $i$; and $e_{i}$ reflects the individual's evaluation and the subjective importance of its consequence. The formula above indicates that for an attitude to change, either one's belief structures or the evaluation of those belief structures needs to be changed. That means that the external stimuli can only influence the attitude change through modifying one's belief structure [15].

\section{Subjective Norm}

SN (Subjective Norm) calculates the collection of all the normative beliefs, which are the individual's perception of what people important to her/him think that her/his behavior should be $\left(\mathrm{nb}_{\mathrm{i}}\right)$, multiplied by the degree of individual's motivation to comply with each of those beliefs $\left(\mathrm{mc}_{\mathrm{i}}\right)$ :

$$
\mathbf{S N}=\boldsymbol{\Sigma} \mathbf{n b}_{\mathbf{i}} \cdot \mathbf{m} \mathbf{c}_{\mathbf{i}}
$$

TRA asserts that influencing behavior is only possible through influencing attitude (A), subjective norm (SN) or their corresponding weights. Given that TRA is a general social psychology theory, it does not identify the set of beliefs that influence specific behaviors. Fishbein and Ajzen advise that researchers need to discover those beliefs important to the behavior being studied. They suggest identifying those key-influencing beliefs (5-9 key beliefs), by the researcher(s) conducting free response interview of sample members of the studied population to collect the most common beliefs [96].

As Fishbein and Ajzen stated: "TRA mediates the impact of uncontrollable environmental variables and controllable interventions on user behavior" [96].

\section{3) Application and Extension}

Since its conception, TRA has been applied to many applications including health intervention and HTA [97], [98]. Fishbein et al. applied TRA paradigm to the underlying factors deriving AIDS related behaviors to suggest strategies for intervention and education plan implemented in communities to alter those behaviors [99]. TRA was utilized for the study of internal psychological variables influenced by the external factors in information systems researches that investigate user acceptance [17].

Prin and Mills studied the nurses' MEDLINE usage using TRA which highlighted the nurses' attitudes towards research significantly influencing MEDLINE usage and MEDLINE usage correlating with nurses' research utilization [97]. TRA has also been used as a general term for the category of theories stem from TRA, like TPB and UTAUT [100]. The theory has also been used to inform the studies in HTA and integrated with other technology adoption theories for better utility [98].

TRA has also been utilized to establish the initial framework and then modified and added upon to achieve more enhanced empirical model that incorporate additional drivers and relations believed missing from the theory. For example, Zhang et al. also, in their study of Mobile Health services adoption utilized TRA, however had to modify the theory to incorporate the nonlinearities between attitude and subjective norms and the moderating effect of gender. The study found that adding nonlinearity enhanced the explanatory ability of the model and that the adoption intention is higher among men and that the TRA model has a higher predictability for men than women [101].

\section{4) Evaluation}

Sheppard et al. meta-analysis across 87 studies using TRA found an average correlation of $66 \%$ for relation between attitude/subjective norm and intention and $53 \%$ for the relation between intention and behavior; concluding that TRA has a strong predictive capability [102]. Chalmers claims, theory of reasoned action with its general claim about the world, which can be easily falsified, make a valuable theory [103]. However, there have been many studies challenging some of the fundamental assumptions of TRA [103]-[106]. The overarching criticisms to this theory are mainly around three TRA fundamental assumptions of 1) the relations between cognitive and normative structures toward behavior intention is in one direction, 2) these structures are independent and 3) these constructs only influence the behavior through behavior intention.

One of the studies that looked into these issues is the research by Shimp and Kavas [104] studying the usage of coupons among consumers. While they verified TRA's success, they also constructed many models to test the interdependent relations between attitude and subjective influence variables. Their findings supported Bagozzi's earlier researches [105], [106], in that the expectancy value can't necessarily add up to a single cognitive value of $\Sigma b_{\mathrm{i}} \cdot \mathrm{e}_{\mathrm{i}}$. 
Additionally the study suggested that the multidirectional representation of cognitive structure in coupon usage accounted for about $59 \%$ of affective based attitude variance, which was a lot more than the unidirectional representation. And in regards to the nature of normative structure $\Sigma \mathrm{nb}_{\mathrm{i}} \cdot \mathrm{mc}_{\mathrm{i}}$, the findings didn't suggest much difference between the effect of the aggregated subjective norms (spouse, other family members, neighbor and friends) and the most prominent one (spouse subjective norm). The study also researched both direct and indirect crossover effects of attitudinal and subjective normative interdependence, which is dismissed by TRA, and is considered as one of the theory's shortcomings. The results reaffirms earlier studies findings of the indivisibility of the personal and subjective normative concepts [104], [107], in that the behavior intention is a product of complex set of interdependent variables and not a parallel, discrete group of beliefs and normative factors [104].

Other shortcoming of the theory is its poor predictability in situations when people have incomplete (or none) volitional control. Revisiting the earlier example where Jane's intention to obtain a remote health monitoring system was being analyzed, based on TRA the aggregated effects of Jane's beliefs about the consequences of adopting a monitoring system in combination with the social norms and its evaluation should result in the behavior intention of obtaining one. However, it's more than often observed that despite those strong positive drivers, the adoption behavior doesn't occur. In such cases TRA can't accurately predict or explain why one does not accept the use of such promising health technologies.

These shortcomings of the theory as also particularly assessed below based on the earlier identified evaluation criteria make TRA unfit for HTA research.

Emotional influences: Regardless of whether the rationality of the theory is arguably dismissing or aggregating the personal and normative emotional drivers, the theory is not reflecting the high inherent influence of affect in predicting behavior intention and or actions known in HTA.

Value sensitivity: TRA due to its emphasis on the personal beliefs seems to be capable of addressing the value sensitivity of health to individuals. Quality or its perception, as a major determinant can be reflected in a model based on TRA and cost benefit rationality can be easily dismissed.

Volitional and self-efficacy: TRA's ignorance of selfefficacy is its major shortcoming, which led to the development of TPB. TRA concepts do not capture behavioral control, a key determinant in health technology acceptance behavior. As literature highlights, self-efficacy is a primary factor predicting one's intention to use a health technology innovation, and ignoring it will make the theory unfit for conducting empirical studies in HTA.

Demographic sensitivity: As highlighted earlier, demographic characteristics such as age and gender are keys in explaining and envisioning one's intention to use a health technology; and planning an intervention program to promote this acceptance using theories like TRA that fail to consider the demographic effects will lead to inconclusive outcome if not failure.

Time sensitivity: TRA's claim of the unidirectional and parallel influences of attitudes and normative beliefs on behavior intention and action neither captures the reciprocal influence of behavior on those factors nor does it consider the mutual salient effects of these determinants on each other over time. The failure to consider the reciprocal effect of behavior on attitude and subjective norm makes the theory time insensitive and hence incapable of differentiation between initial adoption and long-term adherence to the technology usage in healthcare.

Practicality: TRA with its broad-reaching definition of belief and social normative factors influencing intention and therefore behavior, is lacking the granularity required for guiding a HTA related research. The theory needs to be decomposed to capture at least the known salient beliefs, attitudinal factors and major social determinants to depict a more comprehensive image of the influence of those drivers. RTA requires more details so it can highlight specific operationalized findings that can be turned into plan of actions to improve HTA.

Overall given the shortcomings discussed and with respect to highlighted criteria significant in capturing the mental model involved in HTA decision-making, TRA clearly lacks utilization capacity and it is not fit for the study and planning effective health technology acceptance and or diffusion.

\section{Theory of Planned Behavior (TPB) \\ 1) Overview}

Icek Ajzen extended the Theory of Reasoned Action to Theory of Planned Behavior in 1985 to improve the predictability of human behavior [95][108][109]. He integrates SCT's self-efficacy concept, as perceived behavioral control factor with TRA's internal attitudinal factors and external subjective norms to more accurately model behavior intention. The resulting theory is the Theory of Planned Behavior [108]. Revisiting this paper's example, TPB would predict that if Jane were not confident that she can use remote health monitoring system, she would most likely not intend obtaining one.

TPB formula similar to TRA, sums up attitude (A) with subjective norm (SN), but also incorporate perceived behavioral control (PBC) that together influence the behavior intention (BI). The following formula and figure exhibit how behavior intention becomes a function of attitude, subjective norms as well as the perceived power of control factors adjusted with their corresponding powers.

$$
\mathbf{B I}=\mathbf{A}+\mathbf{S N}+\mathbf{P B C}=\Sigma \mathbf{b}_{\mathrm{i}} \cdot \mathrm{e}_{\mathrm{i}}+\Sigma \mathbf{n b}_{\mathrm{i}} \cdot \mathbf{m} \mathrm{c}_{\mathrm{i}}+\Sigma \mathbf{p}_{\mathrm{i}} \cdot \mathbf{c}_{\mathrm{i}}
$$

TPB also posits that Perceived Behavior Control also influences Behavior directly, particularly when behavior is controlled by the individual: $\quad \mathbf{B}=\mathbf{B I}+\mathbf{P B C}$ 


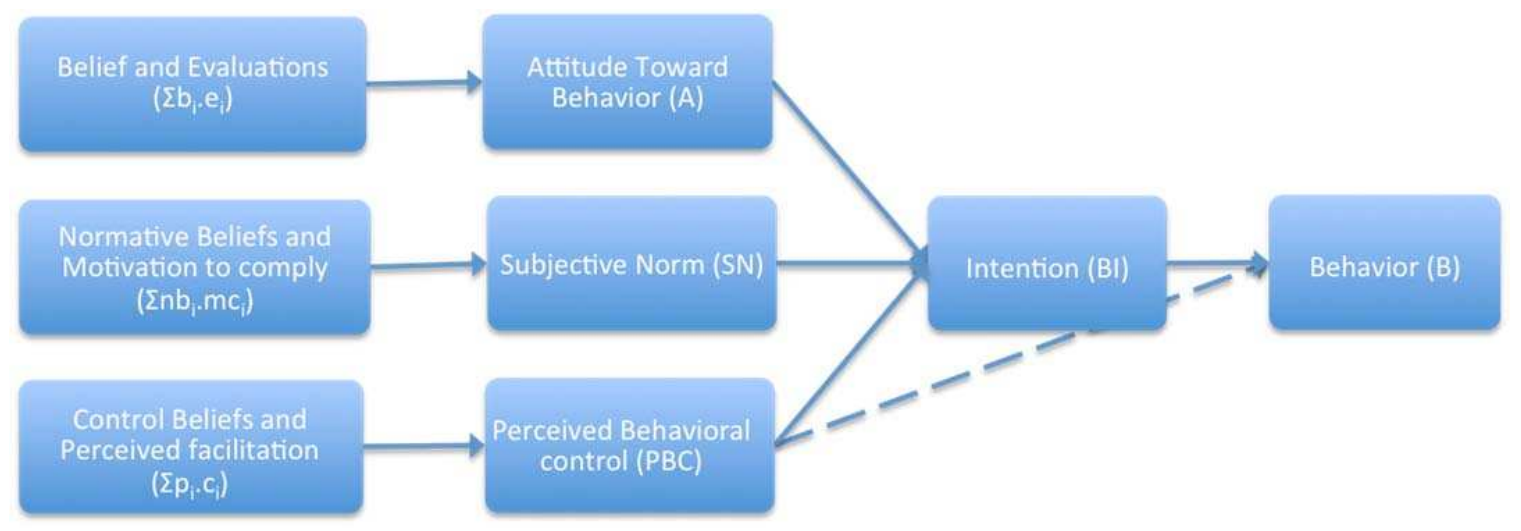

Figure 4 - Theory of Planned Behavior [108]

\section{2) Concepts}

Attitude Toward Behavior Identified in section II.B.2. Subjective norm Identified in section II.B.2.

\section{Perceived Behavioral Control}

PBC represents the aggregated influence of all the individual's perceptions about the easiness or difficultly level of performing the considered behavior, multiplied each by the strength of that belief.

$$
P B C=\Sigma p_{i} \cdot c_{i}
$$

Here, $\mathbf{p}_{\mathbf{i}}$ represents the perceived strength of the control belief and $\mathbf{c}_{\mathbf{i}}$ reflects the individual's attention strength to that belief [110].

\section{3) Application and Extension}

Many studies provide evidence to TPB's superiority over TRA in better predicting health related behavior. The advantage of TPB becomes more evident in applications where lack of confidence or control over behavior plays an important role in predicting the behavior [111]. Utilizing TRA and TPB, Fishbein spent much effort contributing to HIV prevention [112]. Numerous successful health behavior interventions have been implemented using TPB. These range from many healthy eating intervention programs [113][114], weight management planning [115], [116], exercise promotion researches [117], and health policy making [118] to the many studies of HTA [119]-[121].

Heart and Kalderon used TPB in their study of older adults' adoption of Information and Communication Technologies (ICT) to assist in delivering cost-effective elderly healthcare. They examined TPB's validity and found that it was partially effective as they only found perceived behavioral control significantly affecting the intention to use ICT. They also observed 'health' moderating the effect of age in the rate of adoption [119].

Leblanc et al., using modified version of TPB, studied the adoption of electronic health record plan nationally being developed in Canada to identify intervention plans to improve nurses usage. The implication was to invest on intervention plan that strengthened nurses' belief that EHR usage improves the quality of patient care [120].

Deng et al. explored a research model of the adoption of mobile health services in China among older people and the middle-aged using TPB combined with the value attitude behavior model and adding four aging characteristic constructs [121]. Another application of TPB, was the study of gender differences in the process of technology adoption decision by Morris and Venkatesh [122]. The findings depict that TPB's major constructs have different degree of importance between women and men; and suggest men to have more objective and instrumental behavior whereas women to be more aware of social cues and assign more values in the interpersonal relationship. The research shows that as a determinant to use a system, while attitude toward adoption influence men the most, subjective norm and perceived behavior control (both as a determinant of behavior intention and usage behavior) are the more salient drivers in women. They suggest that these findings not only apply to the initial usage intention but also pertain to sustained usage behavior [122].

\section{4) Evaluation}

Godin and Kok [123] studied many applications of TPB in health related behaviors [123]. They discovered that while TPB concepts explain significant part of the variance in intention and in some cases in behavior, there are additional concepts important in healthcare behavior that TPB doesn't encompass. The two main categories of factors discovered were 1) personal norm (own identity expecting how to behave) and 2) moral norm (self-sense of responsibility). Personal norm could be a product of individual's gender, age, relationship and socioeconomic status. Moral norm is individual's feeling of own responsibility. The study also showed that strengths of the influences of these factors are not the same in different health applications. For example while personal norm (self-identity factor) is an important variable in the organic product consumption, moral norm factor play a more significant role in smoking cigarette, driving behavior, condom usage or exercising [123]. 


\section{Proceedings of PICMET '15: Management of the Technology Age}

The need for additional construct based on the applications have been recognized by Ajzen. While he argues that the theory covers all the major determinants of intention he declares that the theory is open for additional determinants [110]. The criterion for this inclusion is that the new determinant explains a significant portion of the variance in prediction of either intention or behavior after consideration of the existing variables in the theory [110]. However, sometimes this inclusion makes the theory redundant. For example, TPB with the addition of such factors becomes very similar to Triandis Interpersonal Behavior theory, another behavioral theory similar to TPB that incorporates habit and facilitating conditions affect into behavior prediction [124].

Empirical studies provide evidences to the benefit of combining theories to create more effective health behavior intervention program. A study into behavior intervention using TPB versus, TPB and implementation intentions intervention found the result from the latter approach more effective. In this research of snacking behavior intervention among girls in ten middle school in Iran, while both approaches were successful, combined TPB and implementation intentions intervention was a more effective approach in behavior intervention and had a longer lasting effect [125].

Conner and Armitage reviewed empirical and theoretical evidences supporting the needs for extending TPB [126]. They identified and suggested the addition of six variables such as affective beliefs, belief salience measures, past behavior/habit, perceived behavioral control (PBC) vs. selfefficacy, moral norms and self-identity [126].

With respect to the HTA evaluation criteria identified earlier and as described below TPB does not qualify as an adequate theory to study HTA.

Emotional influences: When analyzing health technology related behavior, perhaps one of the most important shortcomings of TPB (similar to TRA) is its failure to fully capture the influence of emotional factors into those behavior intentions, which leads to poor predictability [127]. This criticism is challenged by Fishbein's claim that these theories do not deny or contradict emotional determinants as well as irrationality of behavior [34]. Nonetheless, research on the role of effect on TPB variables in health related decisions shows that affect mediate both the influence of perceived behavioral control as well as attitude on the behavior intention, and hence it's significant to be explicitly considered [23][128]. And research in extending TPB for future research emphasize on addition of the emotion factor [126] since these non-cognitive factors are particularly important in the study of health technology acceptance/adoption, TPB's ignorance to these variables, make it less than appropriate to research HTA.

Value sensitivity: Similar to TRA, TPB's primal emphasis on the personal belief and its possible irrationality as Ajzen and Fishbein postulate [15], makes the theory capable of addressing the value sensitivity of health to individuals. Hence utilizing TPB, quality or its perception, as a major determinant can be reflected in a model.

Demographic sensitivity: The insensitivity to demographic characteristics in general and age and gender in particular, doesn't facilitate modeling and reflecting the effect of such salient factors' in health adoption; and makes the empirical study impotent to lead to adequate and tailored intervention plans that best fit the need of the group focused on. This is also evident by Hagger et al. finding that the utility of TPB is dependent upon the type of the population and that the younger adults have different predictors to their behavior compare to the older demographics [129].

Volitional and self-efficacy: compared to TRA, TPB has taken a big leap forward in explaining HTA. As established by much conducted research, perceived behavioral control is the key in determining human's decision to use technology in general and health technology in particular [59], [70]. In fact, TPB's consideration of dual role of PBC in influencing both the intention as well as co-determination of behavior, as supported by many studies [130]-[132], make it more sensitive to this salient factor in HTA; and hence making it relatively a powerful theory in capturing volitional control role in HTA.

Time sensitivity: TPB is more conclusive than TRA in that it has evolved to incorporate the volitional controls as important determinants of health technology behavior. However just like TRA, TPB's inherent characteristic considers the influence of attribute, subjective norm and behavior control only in parallel and unidirectional toward behavior and behavior intention. This neither allows modeling of the influence among these factors, nor can capture the effect of initial behavior (acceptance) in the longterm adoption.

Practicality: Much of the studies that have utilized TPB, and in particular the more recent ones in the domain of HTA, have had to either combine it with other theories [125], extend it [126] and or add variables to it to enhance its practicality [122]. In fact this need for addition of concepts based on the applications have been recognized by Ajzen [110] and its extension to integrated more variables (such as affect important in the study of HTA) have been acknowledged and well accepted [126]. Given the complexity of HTA and diversity of determinants involved, it is concluded that TPB lacks the capacity for conducting research in HTA.

\section{Reasoned Action Approach (RAA) (Integrative Model (IM))}

1) Overview

Fishbein postulates that "what the reasoned action approach attempts to do is to identify a relatively small set of variables that can account for a substantial proportion of the variance in any given behavior" [34].

Rooted in the theory development in 1967 [94] and the continuation of theory evolutions [112][95], integrated model of Reasoned Action Approach was established in 2010 [96]. 
Similar to its parent theories of Theory of Reasoned Action and Theory of Planned Behavior, RAA considers intention as the prime antecedent of behavior. However, it acknowledges that the environmental and personal factors such as individual's skills and abilities can influence the relation between intention and behavior. Significantly, in this integrated model as depicted in Figure 5, Fishbein addresses the criticism to the two earlier theories of Reasoned Action and Planned Behavior by adding the entire category of "background influence" to the model. He argues that based on the developing consensus [133] that the model should incorporate as limited number of factors as possible that can account for the most variance of any given behavior, those emotional factors do not need to be explicitly placed in the model. RAA claims that mood and emotion as background variables influence one's perceived reality (and that of the people around), and hence their influence is captured through the individual's beliefs (and subjective norm). Human reasoning is subjective and built as the product of learning about the world and the beliefs, perceived social norms and controls that are shaped overtime. All these factors, from individual's past experiences, the culture lived in, social stigma and values perceived, and own personality, moods and emotions, inclusively create what the person believes in; and how those beliefs are evaluated; how the pressures around is interpreted and complied with; and how much control over those perceived powers one holds. This subjectivity explains how an action can look irrational to an observer while being perfectly sensible to the actor [34].

As depicted below, based on Reasoned Action Approach, while intention dictates behavior, perceived behavior control mediates it. Intention is (similar to TPB) a function of attitude, perceived norm, and perceived behavioral control:

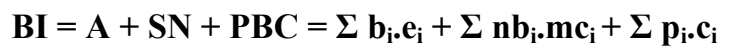

However RAA contains a feedback loop in that the previous performed behaviors and experiences add up to the background variables influencing the three predominant factors that drives behavior intention as depicted below [96].

Reasoned Action Approach is the result of a four-stage evolution of the behavioral theory within four decades [134]. It started by Fishbein creation of TRA in 1967 as detailed earlier [94]. Despite TRA's relative successful performance at the time, Ajzen realized its deficiency in predicting behaviors due to the ignorance of volitional control. He addressed this by adding the perceived behavioral control as the immediate antecedent to intention and a moderator to behavior, which resulted in creation of TPB in 1985 [108] [109]. Further development occurred when National Institute of Mental Health invited a group of theorists including

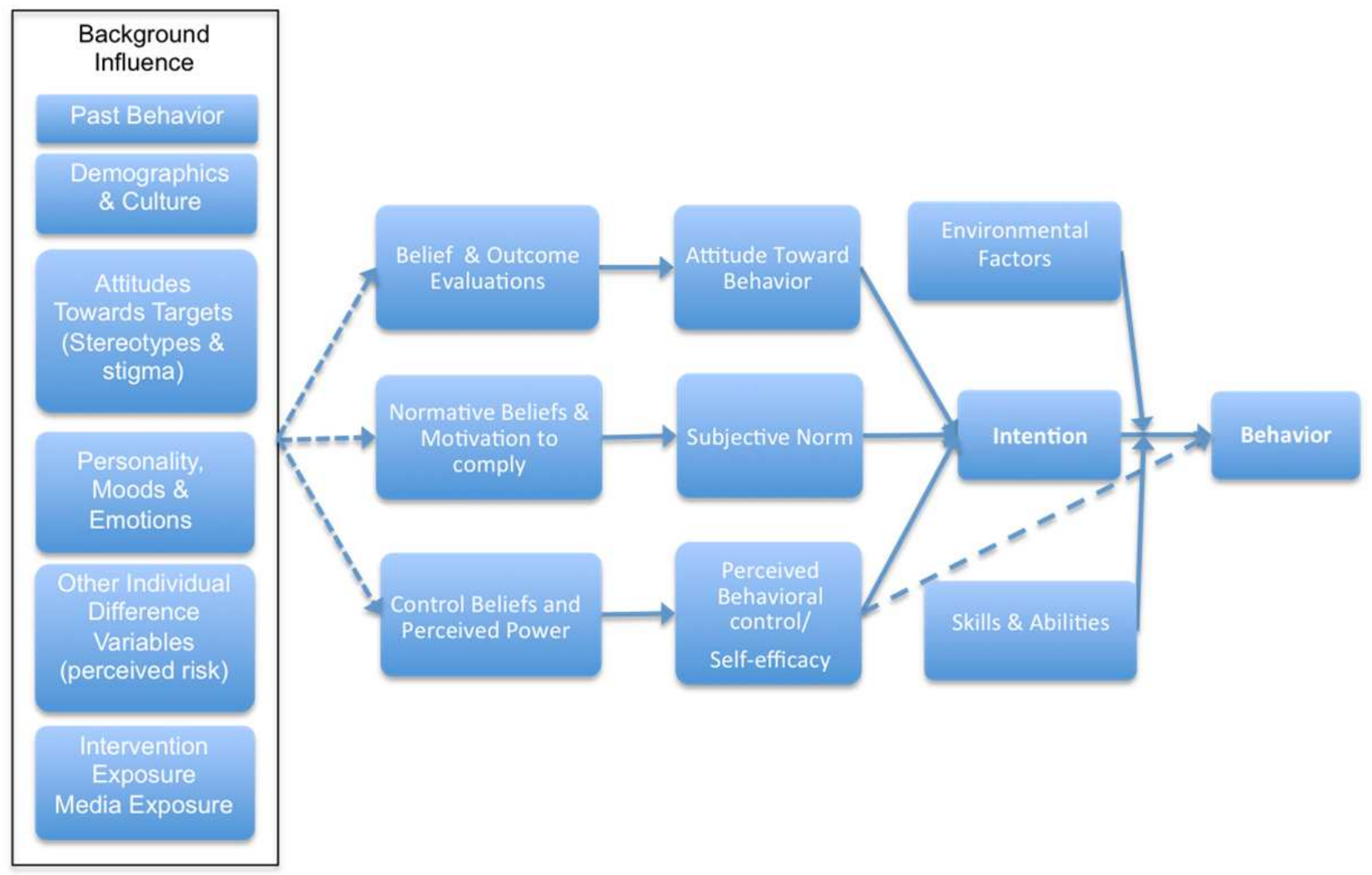

Figure 5 - Reasoned Action Approach [96] 
Bandura and Fishbein to collaborate on development of an integrated model for health behavior [133]. The Integrated Behavior Model (IBM) merged the predominant factors of earlier behavioral theories such as SCT, TRA, TPB, Health Behavior Model (HBM) [135] and Theory of interpersonal behavior [124]. The final stage was when Ajzen and Fishbein tried to consolidate their works and realized that their separate research was taking them to the same direction and the integration of those researches led to the birth of Theory of Reasoned Action Approach [112].

A cursory review of Health Behavior Model (HBM) [135] indicates three set of predominant factors as: need for care, inclining (family, health belief, social settings) and enabling (economic factors and access to health providers) constructs that influence health behavior [135].

Fishbein brings two important points to attention: 1) there is a difference between predicting or intervening particular behaviors (e.g. eating more fruit and vegetable) and a group of behaviors or goals (become more healthy); and 2) a behavior is constructed of four elements: action, target, context and time (an action conducted to reach a target in a particular context at a given time). He posits that Reasoned Action Approach provides a more accurate model for investigators to design effective health behavior intervention program [96]. RAA facilitates understanding of the factors inhibiting healthy behavior and allows for intervention plan focused to address those factors, as opposed to the popular interventions such as trying to raise knowledge or change the attitude. While intention is still considered as the predominant predictor to the behavior, it does not always lead to the corresponding behavior. As highlighted by RAA, this could be due to many internal reasons like lack of ability or skills needed, and or external environmental constraints. So if the patient has the right attitude but not conducting the necessary action due to lack of skills, then naturally the intervention plan should aim at building the skills. The diversity in the inhibiting variables calls for different intervention plans to address the root cause. Additionally, the importance of the attitudinal versus normative variables on behaviors is not only different in various behaviors; it is also a function of the population the behaviors is studied in. So, one behavior that is entirely attitudinally influenced in one environment could be normatively influenced in another. This explains the discrepancy of behavior antecedents among different demographics [129] and why a successful intervention in one population could be a total failure in another [34].

\section{2) Concepts}

Attitude Toward Behavior Identified in section II.B.2.

Subjective norm Identified in section II.B.2.

Perceived Behavioral Control Identified in section II.C.2.

\section{Environmental Factors}

These are the barriers or promoters in the environment that directly influence the performance of behavior.

\section{Skills and Abilities}

Individual's personalities, different abilities and skills built over time that directly influence the performance of the behavior.

\section{Background Influences}

These are the entire sets of factors that influence individual's belief system and attitudes, subjective norm and self-efficacy related behavior controls. They range from personal to social factors including past behaviors and experiences, individual demographic characteristics, personal emotional drives, moods and traits, cultural norms, stereotypes, stigma, media and other intervention exposures.

\section{3) Application and Extension}

Despite the fact that Reasoned Action Approach has been developed over a decade ago, and its promising set of extended factors better explain behavior, its application has not been utilized as widely and extensively as the earlier TRA and TPB theories. RAA applications, among others, include many studies of health behavior [33], [136]-[138] and to a lesser extend in researching HTA behavior [139], [140].

McLallen and Fishbein applied RAA to study the role of attitude, social norm and perceived behavior control as predictors of intention to perform six different cancer related behavior. 1753 men and women with different ethnicity, aged 40-70 and living in US were surveyed about their intention to take tests like colonoscopy, mammogram (for women population) and Prostate (for men population) as well as dieting, eating healthy and exercising. The study finds that attitudes, normative pressure, and perceived control significantly predict (accounted for between $44 \%$ to $54 \%$ of the variance) intentions to engage in these 6 behaviors. Interestingly, for different behavior function, the study suggests different level of importance for these three considered variables. For example normative pressure was the most important determinant of intention to take colonoscopy or PSA test but not a significant driver for exercising. These findings suggest that to increase the intention of taking those tests the intervention need to increase the normative pressure while this approach should be avoided for promoting exercise [137]. Pasick et al. also studied perceived benefit, perceived susceptibility, selfefficacy, intention, and subjective norms as the frequent factors on mammography utilization studies on 1,463 women from five ethnic groups using RAA. While RAA provided a great theoretical base for the study the findings suggested that (despite what the model theorizes) social context can bypass the intention and directly influence behavior. This study highlights the importance of utilizing a well-tested approach as opposed to inventing or perhaps reinventing it. However, the findings also emphasizes on the rigorous process evaluation. Their multi-perspective research has stressed on the significance of inclusive community-based program development that not only creates credibility but also makes it more effective and desirable [141]. 


\section{Proceedings of PICMET '15: Management of the Technology Age}

\section{4) Evaluation}

Reasoned Action Approach is a superior theory to its predecessors in that it facilitates changing behavior not only by mending the salient beliefs influencing the intention but also through expanding skills and overcoming the external barriers. Many meta-analysis reaffirm RAA validity [143], [144]. However, the claim of sufficiency of RAA is the subject of many interrogations [23], [144]. While Ajzen argues that the theory covers all the major determinants of intention he declares that the theory is open for additional determinants with the criteria described earlier (in TPB section) [134].

In the development of Reasoned Action Approach, many of the criticisms to the earlier theories, TRA and TPB were addressed when additional external and internal factors, proven influential to behavior, were added to the model. Over four decades of evolution has made RAA the most potent in its chain of theories to predict [145] and intervene in behavior [143], making it a popular theory for the study of health behavior [141], [147]. However, scholars argue that this long development period has done little, as today's RAA is not too different from the original TRA over forty years ago. One of the most frequently applications these theories have been utilized in is health related behavior, yet some of the most influential categories of factors driving health behavior are missing or only added as background influence [15]. The model is argued that should be more open to changes beyond the current three main determinants [15]. For example Selfidentity, a key factor claiming a considerable variance in both intention and behavior prediction, is dismissed from the theory. While Fishbein and Ajzen have claimed to be open to new variables [17], the criteria for adding the fourth construct have been too rigorous for any factor to qualify [134], [147] . Additionally below is the assessment in regards to the criteria identified in this paper for the study of HTA.

\section{Emotional influences}

As mentioned, emotional factors are powerful drivers influencing and hence describing health decision-making and often its irrationality. RAA, with embedding mood and emotional drivers as the background influence, has taken a leap forward in qualifying for studying HTA. However, evidences identify these factors as much more significant in health related decision and particularly in HTA [47], [48], and considering emotion as a cursory measures in RAA, does not facilitate capturing their salient influence. According to RAA, emotion can only affect the intention and behavior through the three parallel attitudinal, social normative and volitional influence, which is not coherent with the evidences that emotion can directly influence intention and behavior [144].

\section{Value sensitivity}

Similar to its founding theories, RAA emphasis on the attitudinal and normative factors as primal determinants, make the theory potent in capturing these non-cognitive factors' significance in health technology acceptance [66], [142].

Similar to TRA, TPB's primal emphasis on the personal belief and its possible irrationality as Ajzen postulates [15], makes the theory capable of addressing the value sensitivity of health to individuals. Hence utilizing TPB, quality or its perception, as a major determinant can be reflected in a model.

\section{Demographic sensitivity}

As highlighted there are overwhelming amount of evidences about the influence of demographical characteristics, particularly gender and age in how the health technology adoption decision-making is made [56]-[61]. Studies highlight those factors among the most important ones and suggest that the impact of the intervention plans is contingent on them. Given the significance of such factors, HTA and RAA incorporation of demographics is a significant step forward in its potency compared to the earlier theories. However, as evident by empirical studies, demographic determinants' roles (particularly age and gender) are observed to be much greater than being categorized as background factors [129]. Therefore RAA is undermining these factors and unless paid attention, the theory is not able to fully reflect their influence.

\section{Volitional and self-efficacy}

In addition to its inherent consideration of perceived behavioral control and its effect on both intention and behavior, other significant attributes of theory that make RAA a relatively better candidate for studying healthcare technology adoption are the inclusion of individual's skills and abilities, that directly moderate the adoption behavior. These comprehensive properties along with the inherent concept of perceived behavior control, better reflect the influence of volition, key in technology acceptance [70], and hence facilitate modeling a more realistic environment for the study of health technology adoption.

\section{Time sensitivity}

The background influence category of determinants driving all the major concepts of the theory facilitates the time sensitivity nature of HTA studies. The past behavior component of the background influence category of factors allows the experience of the initial usage (e.g. experienced usefulness) to influence and shape user's belief as to whether the system should be further used and if she/he is capable of adopting it, which in turn it can explain the consequent usage behavior. Also as the user is experiencing the usage, learning and developing skills, 'skills and abilities' concept of the theory can moderate the future adoption behavior. These considerations make the theory sensitive to the variable of time and hence RAA is capable of differentiating and modeling the initial acceptance versus long-term adherence to the health technology. 


\section{Practicality}

Overall, relative to the earlier theories, RAA is the more preferred theory for the study of technology acceptance in healthcare. Through a long evolution and test of time, salient drives have become integrated into the theory. While these additions make RAA a better and more comprehensive model for explaining human behavior, its capacity to fully capture the mental mode of adoption of healthcare technology is debated [144]. One striking observation is the lack of RAA usage in the study of HTA despite its popularity in studying health behavior studies [138], [145], [148]; as at the time of this report there are only one HTA study using RAA publication in PubMed [149] and not many in Google scholar. While this scarcity could be attributed to RAA relative newness, it could also be due to RAA shortcomings such as being too dependent on the intention [144]. The metaanalysis of 47 tests to investigate the effect of change of intention in behavior change by Thomas and Sheeran showed that a medium to large sized change in intention only created a small to medium change in behavior and the future behavior changes should consider the non-intentional paths to action like automotive(s) and prototype perception(s) [144]. Additionally, Gaither et al. research showed that in health decisions, past behavior directly affected intention to use, which is not possible through modeling in RAA [145]. Based on these observations while RAA is shown to have evolved to a much better theory for studying HTA, it is not ideal and there should be careful considerations to capture the complexities involved in such studies.

\section{E. Hierarchical Model of Intrinsic and Extrinsic Motivation (HMIEM) and Motivational Model (MM)}

1) Overview

Rooted in psychology [150] the motivational concepts have been the center of both Davis et al.'s 1992 Motivational Model [151] as well as Vallerand's 1997 theory of Hierarchical Model of Intrinsic and Extrinsic Motivation [152]. They posits that motivation is the main driver of human behavior Vallerand categorizes motivation to two main groups of intrinsic and extrinsic and argues that they are both key in driving one to conduct an action. The intrinsic motivation is the natural sense of joy, curiosity or interest that internally drives human to conduct a task. Vallerand argues that intrinsic motivation is a critical element in cognitive, social and physical development and those with stronger intrinsic motivation are more likely to engage in the activity and hence develop their skills and capabilities. He states that having sense of control or autonomy as well as desire for mastery aside from external rewards strengthens intrinsic motivation [152]. Extrinsic motivation is the other main group of driving forces behind human behavior. These motivations are any external drivers such as reward, punishment or competition that positively or negatively reinforces, inhibits or compels the behavior. Needs as identified in Maslow's hierarchy of needs (for 1.Physiological needs, 2.Safety, 3.Love, 4.Esteem, and
5.Self-Actualization) [153] are the major underlying drivers of motivations.

\section{2) Concepts}

\section{Intrinsic motivation}

These are the internal factors deriving the performance or avoidance of a behavior. These motivations can be result of natural sense of joy, interest, autonomy, pride or curiosity and they stimulate the behavior outside any external factors.

\section{Extrinsic motivation}

It refers to the external stimulants that influence the performance of an activity or behavior. The positive reinforcements motivates individual to conduct an activity and could be financial (such as bonus salary) or non-financial (like trophy). The negative inhibitors such as punishment inhibit the performance.

\section{3) Application and Extension}

The theory has been applied in various fields, particularly psychological development, education and in some technology adoption. Most of the applications have studied the motivational effect of relationships like those of teacher and student in the educational space [154], [155] or coach and athlete in the sport environment [156]-[158]. In the study of academic performance, Wentzel and Wigfield research suggest that social motivation processes drive academic performance. The findings highlighted that school socializations in general and teacher student interpersonal relationships in particular are key factors driving students' motivation and performance [159].

Davis et al. utilized this model to study the usage of computers in workplace. Their findings suggest that beside the earlier research that considered perceived usefulness as the major determinant for intention to use computer, enjoyment is also identified as a dominant factor in computer usage. In this study usefulness and enjoyment are found to be both mediating the intention to use, perception of the quality of outcome as well as perceived ease of use [151].

Venkatesh and Speier used HMIEM to study and assess the best training method to help teleworkers adopt those technologies and overcome social isolation. They found that using game-based training best facilitates training by increasing users' intrinsic motivation which lead to increased adoption intention [160]. In another study, Venkatesh merged TAM with the concepts of HMIEM to study the effect of intrinsic motivations such as playfulness and emotions like computer anxiety on perceived ease of use over time. They found that with the increase in the usage, perceived ease of use becomes more dependent on objective measures such as usability, external controls, and system-specific perceived enjoyment [52].

\section{4) Evaluation}

Emotional influences, Value sensitivity, Demographic sensitivity and Volitional and self-efficacy: The 


\section{Proceedings of PICMET '15: Management of the Technology Age}

parsimonious nature of HMIEM doesn't highlight any of these salient drivers influencing the adoption in the healthcare domain. Unless the research is made aware of these significant determinants the Intrinsic and Extrinsic theory cannot guide in identifying them. For example, in the study of elderlies' motivations toward physical activity, Dacey et al. had to delineate age and gender as moderators [161].

Time sensitivity: Unless HMIEM is integrated with other theories or concepts that consider time as a variable, HMIEM by itself does not provide the ground to study the time sensitive nature of HTA studies. Thong et al. combined HMIEM with expanded Expectation Confirmation Model [162] to study long-term technology adoption. They included the post-adoption level of intrinsic motivation of enjoyment and perceived ease of use expected in increasing user satisfaction and therefore technology adoption [163].

Practicality: While the Motivation Model propose a realistic look into human behavior and different motivational factors including anxiety, joy and playfulness, it is too parsimonious. As utilizing a behavior theory is favored for the framework it provides directing the attention to the factors that need to be paid attention to and different perspective into the determinants involved, the two main categories of Motivational Model is too reductive or abstract and often used to supplement a main theory[52].

Verhagen et al. utilizing Motivational Model studied users' motivation to engage in virtual world. They demonstrated that the theory is a solid framework to predict behavior in the context of participating in virtual world. However, to overcome the theoretical limitations, they also suggested that it's more beneficial to combine Motivational model with other theory/theories such as TAM for more comprehensive study of the relative contributions of different determining perspectives [164].

Overall, although the theory is conceptually valid and represent a holistic picture of drivers in one's behavior, it lacks the detail required to study influencing and mediating factors involved in the adoption of a technology in a healthcare application. It dismisses the major mediating factors such as demographic characteristics required for empirical studies in this field. Additionally, Its lack of awareness and judgment of time disqualifies it as an adequate theory for research into the short time versus long-term acceptance of health related technologies.

\section{TECHNOLOGY ADOPTION/ACCEPTANCE THEORIES}

This section reviews the most popular technology adoption theories as the foundation of best practices in empirical studies in technology adoption. As depicted in Figure 1, the advent of these theories goes back to 1980's not far after the emergence of computer technology in commercial market. Just like the issue of adoption of technology in healthcare today, the promise of high efficiency of technology has only been realized through adoption among its user. And the conception of these theories have been instrumental in materializing technology diffusions ever since. Some of the most prominent theories in studying technology adoption: Technology Acceptance model (TAM), Model of PC Utilization (MPCU), Innovation Diffusion (IDT), combined TAM and TPB (C-TAM-TPB), TAM2 and Unified Theory of Acceptance and Use of Technology (UTAUT) are reviewed here.

\section{A. Technology Acceptance Model (TAM) \\ 1) Overview}

Davis introduced an adaptation of TRA, the technology acceptance model (TAM) in 1985. As its name suggests TAM was originally designed to explain computer usage behavior. TAM uses reasoned action as the theoretical basis to model the influence of perceived usefulness and perceived ease of use on the attitude and intention to use computer as well as ultimately the actual technology acceptance behavior. While TAM is one adoption of and less general application of TRA designed to model computer usage, decades of research and accumulative findings in information systems, bring evidence as to TAM's capability of explaining technology innovation acceptance in many context and applications [24], [165].

Similar to TRA, TAM postulates that computer usage is determined by behavior intention (BI), but differs in that $\mathrm{BI}$ is viewed as being jointly determined by the person's attitude toward using the system (A) and perceived usefulness (U), with relative weights estimated by regression:

$$
\mathbf{B I}=\mathbf{A}+\mathbf{U} .
$$

A is jointly determined by perceived Usefulness $\mathbf{U}$ and perceived Ease Of Use EOU, with relative weights statistically estimated by linear regression:

$$
\mathbf{A}=\mathbf{U}+\mathbf{E O U}
$$

TAM simple adaptation of TRA is depicted in Figure 6 below.

\section{2) Concepts}

\section{Perceived Usefulness}

Perceived usefulness (U) is defined as the prospective user's subjective probability that using a specific system will increase his or her job performance.

\section{Perceived Ease of Use}

Perceived ease of use (EOU) refers to the degree to which the prospective user expects using the target system to be free of effort. 


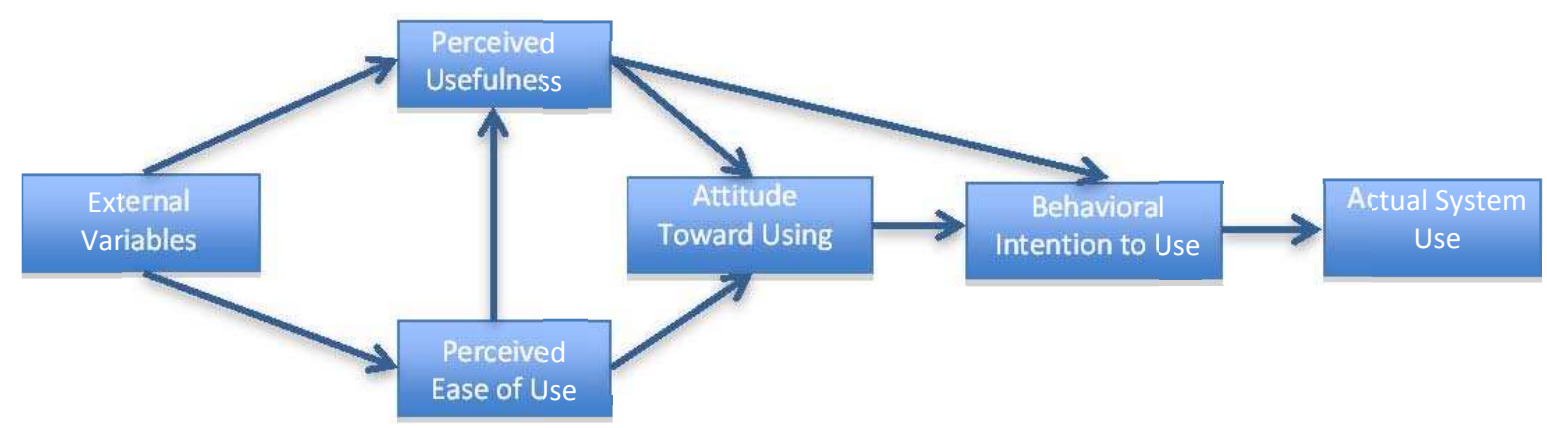

Figure 6 - Technology Acceptance Model [164]

TAM core constructs distinguishes two basic mechanisms influencing attitudes and behavior: self-efficacy (EOU) and instrumentality (U).

\section{3) Application and Extension}

TAM has had a spectacular success in its own acceptance. The citation of the Davis et al. article about TAM alone [165] reaches over 11,100 to date. TAM has been applied for studying the technology acceptance in almost every field. In healthcare technology innovation studies, TAM has been applied to a wide range of applications such as studying the physician's acceptance of Telemedicine [24], designing effective health information websites [166], and assessing the ludic engagement acceptance in rehabilitation [167] In the assessment of ludic engagement using TAM, the findings suggests that while natural technological evolution enhances acceptance of ludic engagement in rehabilitation, the rate is slow and the public programs that compensate for those investments are the strongest driver for expediting their acceptance.

Orruño et al. compared TAM's performance and that of a modified version (with added important factors) to evaluate teledermotology adoption where they found that the modified version became more powerful. Their finding suggested that the most important variable to be the facilitating condition [168].

Venkatech's study looked at how users' perceptions forms and changes over time, what matters most, and what interventions can best enhance those perceptions and the long-term technology adoption. To study perceived ease of use (EOU), he exposed the variable by adding different anchoring variables like control factors (self-efficacy and facilitating conditions), intrinsic motivation (playfulness) and emotion (computer anxiety) that determined early perceptions. With increasing experience, he measured those factors, expecting EOU to adjust to show objective measures such as system related variables such as usability and enjoyment. The model successfully explained EOU in all points of measurement and found the individual's general belief regarding computers to be the strongest driver of EOU even after direct experience; which emphasized on the role of training programs influencing those perceptions which lead to both acceptance and sustained usage [52].
Venkatesh with Morris, using TAM, also studied the role of gender and social influence in technology acceptance and usage behavior. They observed 342 employees' User reactions and new software system usage behavior periodically for five months. Their study suggests that the importance of these factors varies among men and women. Men value perceived usefulness much more; while women were strongly influenced by perceived ease of use and subjective norm factors. These findings, hence, recommended the integration of subjective norm to the model [169]

\section{4) Evaluation}

Davis, Bagozzi and Warshaw published a longitudinal study in 1989 comparing the two theories of TAM and TRA in user acceptance of computer technology application [170]. They researched two fundamental questions relating to the predictability of behavior from intention and the theories' ability to explain intention to use a system. The result of their findings suggests that: people's computer use is indeed predictable from their intention; the perceived usefulness measure is the major determinant; and perceived ease of use is the secondary determinant in people's intention to use computer. The findings further showed that TAM is a more effective model than TRA when it comes to computer usage and that social norm doesn't play a significant role in deriving this behavior (contradicting an earlier study finding social norm as significant driver in women's technology adoption [169]). These constructs were measured again after one hour of practice and instruction where they found a strong correlation between perceived usefulness and intention as well as initial intention and the acceptance of the system [170].

Bagozzi in his view of TAM admires its remarkable performance in technology acceptance predictability. He argues that TAM's main strength is its parsimony. However this parsimony has also become TAM's Achilles' heel in that it dismisses many more determinants in the process of technology acceptance [23]. Additionally, Holden and Karsh assessed TAM suitability in healthcare by reviewing its passed success, acknowledge its outstanding performance in healthcare (and other industries) but raise concern if the model can effectively be utilized as a model of health IT in future. They highlight the need for much improvement before 
the model can be considered as a theory of health IT. They advocate for the theories to be evolved to become more relevant to and fit the needs of healthcare studies. These include allowing for better test of relationships, reporting of data, testing and exposure to more salient variables in particular clinicians' belief in using technology. They suggest that the left side of TAM can be further developed to integrate contextual factors driving the perceived usefulness and ease of use. The expansion is suggested to identify actionable factors, barriers and promoters of IT use in healthcare environment [171]. In regards to the yardstick identified earlier, the following evaluation points out TAM's shortcoming for conducting adequate HTA research.

Emotional influences: While TAM in its simplistic form has captured the pillars of perceptions forming ones intention to use technology, there are many factors driving those perceptions, particularly in healthcare domain. One might have to suppress the emotions like computer anxiety and use the technology where it's mandated. When these technologies are targeting broad range of users like patients from, educationally and socioeconomically diverse backgrounds, the role of emotions become significant and can hinder the adoption. This shortcoming can be overcome, like many conducted studies [44], [166] by expanding the left side of the TAM to include emotional determinants [171]. This necessity makes TAM by itself an incomplete theory for comprehensive studies in HTA.

Value sensitivity: Despite the fact that TAM doesn't contain specific concepts measuring the value sensitivity of health related decision, its emphasis on the perception as opposed to the objective measures tend to capture the sensitivity that doesn't comply with the classic cost benefit analysis, and can reflect the property of those decisions to an extent. However, as confirmed by studies specific to HTA [172], TAM better explains the acceptance when incorporated with the factors highlighting these irrationalities.

Demographic sensitivity: As highlighted by many studies of HTA using TAM, lack of inclusion of demographic characteristics is TAM's major disadvantage in studying HTA. When gender is considered as the moderating variable, it becomes evident that the value and influence of TAM's two salient perceptions are significantly different among the genders [169], [173], and unless modified, TAM's inherent ignorance of these determinants makes the theory unfit for studying HTA.

Volitional and self-efficacy: Self-efficacy established as key in one's decision in HTA, is not explicitly incorporated in TAM. While arguably perceived EOU encompass users' volitional control, as fruitful HTA studies [52] shows, adding those factors empowers TAM utilized researches. Without including those factors explicitly their importance in HTA is not reflected and hence there will not be a complete picture of the adoption process drawn; and therefore the outcome of the interventions plans more than likely will be inconclusive.

Time sensitivity: Similar to the influence of other significant drivers of HTA mentioned above the role of time in the study of initial versus long-term adoption in technological solutions in healthcare domain, is not captured by TAM. Much of the HTA studies that used TAM for looking into the long-term adoption [170], [52] had to add time variable by conducting longitudinal studies and comparing the measures manually. Lack of consideration of how experiencing the technology and initial usage can influence and or change the long-term adoption make TAM impotent for studying such difference key in HTA.

Practicality: Given its simplicity and compared to its counterpart theories, TAM's performance in predicting technology acceptance has been remarkable. However, In consideration of technology acceptance in healthcare applications, TAM seems too simple and naive. As described, lack of attention to emotional, demographic and time variables makes the theory unfit for the study of technology in the complex case of healthcare. Additionally, while there is a placeholder for external factors, the theory by itself does not have the capacity to guide modeling them, and unless the factors are researched and identified (such as Lee et al.'s study that enumerated 21 external variable influencing the four central TAM variables [174]), the model does not provide an inclusive picture of factors involved. TAM, unless is further developed, can't explain the influence of all the personal and environmental determinants important in the health context and hence TAM by in and of itself is not practical enough for empirical studies of technology acceptance and diffusion in healthcare.

\section{B. Model of PC Utilization (MPCU) \\ 1) Overview}

As an alternative model to TRA and TPB and based on the Triandis' theory of human behavior [175], Thompson et al. created Model of PC Utilization [175]. In this model, the use of personal computer is posited to be driven by complexity, job-fit, long-term consequences, affect toward use, social factors and the facilitation conditions as depicted in Figure 7, below.

MPCU theorizes that usage of PC is drived by an individual's emotion toward using $\mathrm{PC}$, the dominant social norms in the environment, individuals' perceived consequences of this use and the existing environment conditions that facilitate this utilization. Their findings suggest that social norms and the three measures of expected consequences (long-term consequences, job-fit and complexity in using the PC) are the major determinants of PC utilization. Given the importance of consequence expectation, the model highlights the significance of facilitating conditions (for example providing training, support and policies) to advance these expectations and ease the perception of complexity. One strategy, as Bandura's SCT also suggest, is to employ a technology enthusiast as a role model to actively use and promote innovation adoption [176]. 


\section{2) Concepts}

\section{Affect toward use}

In the context of MPCU, it represents the feeling toward using PC (or technology in general). As Triandis strives to separate the concept of belief and emotion, he highlights the factor as: "the feelings of joy, elation, or pleasure, or depression, disgust, displeasure, or hate associated by an individual with a particular act." [175]. The model posits that positive affect toward use correlate with higher utilization of PC.

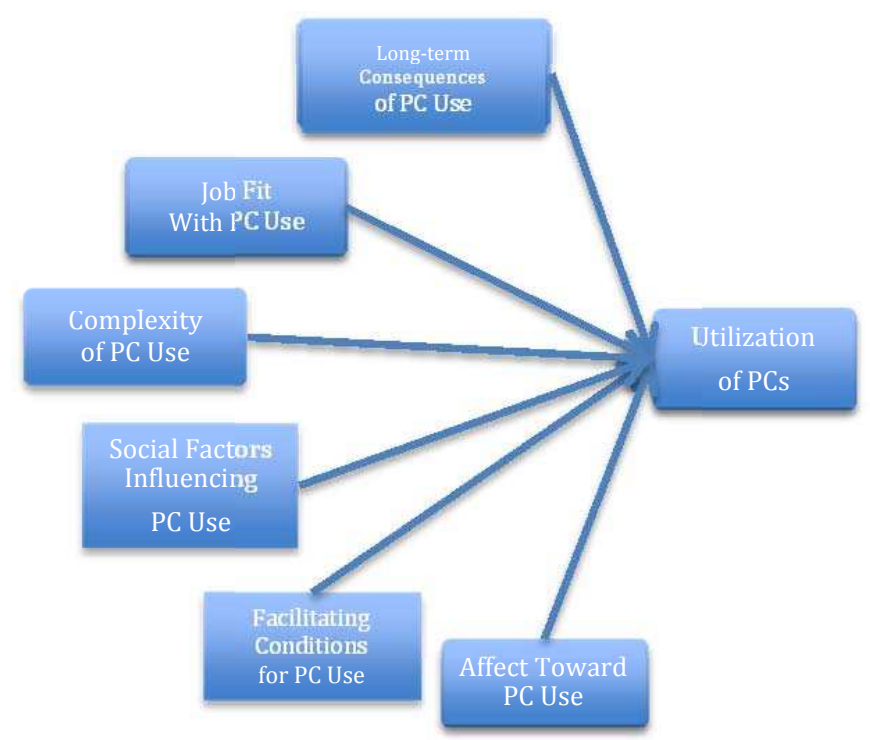

Figure 7 - Model of PC Utilization [175]

\section{Perceived consequence}

Is the expected resulting outcome from using Personal Computer (originally). If individuals perceive that utilizing PC provides value, it's more likely they will accept using it. This construct consists of two near term factors (Complexity and Job-fit as described below) and one future oriented factor (long-term consequences).

\section{Complexity}

Is the degree of efforts one has to make to understand and use PC. This factor is highlighting the reverse effect of perceived ease of use in TAM. The model suggests that complexity negatively influence the use of PC.

\section{Job-fit}

Is the degree in which using a PC is perceived to help enhance user's job performance. The higher this perceived job-fit the higher possibility that the user will utilize PC.

\section{Long-term consequence of Use}

Is the outcome that is realized in the future. These are often rewards that come in the future and at a price of extra efforts at present; such as learning to use PC for a future pay off or changing job. MPCU posits that strong perceived longterm consequence positively influence utilization of $\mathrm{PC}$.

\section{Facilitating conditions}

Are the objective conditions present in the environment that facilitate the utilization of PC. Triandis claims that the behavior can't occur where those environmental conditions prevent it. MPCU posits that facilitating conditions are positively correlated with usage of PC.

\section{Social factors}

Are the equivalent of social norm in TRA and TPB, these are the perceived pressures from the environment around the individual as to what to do and the individual willingness to comply with those norms. MPCU posits that strong social norms to use PC positively influence the individual's PC utilization.

\section{3) Application and Extension}

Although a quick review of the literature doesn't suggest a high rate of MPCU utilization, the model is theoretically significant in its contribution to the incremental theoretical evolution; as well as bringing forward a more comprehensive view that integrates major concepts of the earlier theories important in the adoption of technology. The theory's contribution is significant, as it has laid the ground, along the other seven theories, for creating the Unified Theory of Acceptance and Use of Technology Model, as most of MPCU citations [176]-[179] are in relation to UTAUT (as later explained). Perhaps the most significant characteristic of MPCU (as key in HTA) is its consideration of long-term consequences. This boost MPCU's qualification for studying the technology adoption in applications like healthcare where adherence is more important than the initial adoption. However literature rarely shows much utilization of the theory by itself. Albeit, Model of PC Utilization concepts have contributed to many studies of technology acceptance [180]-[182].

\section{4) Evaluation}

Emotional influences, Value sensitivity, Demographic sensitivity, Volitional and self-efficacy, Time sensitivity, Practicality: As postulated by its founders, MPCU theorizes that usage of PC is drived by individuals' emotion toward using pc [175]. Model of PC utilization has been able to conceptually capture many of the significant determinants in using computer.

Some of the MPCU concepts including 'complexity of PC use' and particularly 'Affect toward PC use' provide the theory with the capacity to integrate some of the significant emotional drivers and value sensitivity in HTA. Additionally, MPCU's attention to the affect toward use is noticeable and promising in incorporating the emotional drivers in the adoption process; and capturing the influence of facilitating conditions and social factors make the theory a better candidate than those (such as TAM) neglecting these factors. 
However, MPCU doesn't consider behavioral control and more importantly ignores the demographic characteristics effects on the utilization of technology. Therefore, despite its potential to explain PC utilization it is incapable of facilitating a practical and holistic research in health technology acceptance and adherence. Like most of other theories in its time, MPCU lacks some of the significant concepts required to study HTA.

\section{Innovation Diffusion Theory (IDT) \\ 1) Overview}

Innovation Diffusion Theory, rooted in sociology, has been utilized in studying innovation in various fields from early 1960's [183]. Rogers popularized Innovation Diffusion Theory (IDT) in 1983 [184]. IDT posits that as people collect, analyze and synthesize information about innovation in their environment, they form perceptions of that innovation. This perception of the innovation, among other drivers, is key in acceptance and usage of the innovation. He claims that main elements in the diffusion of new ideas are "(1) an innovation (2) that is communicated through certain channels (3) over time (4) among the members of a social system." [183].

Most of theories discussed earlier (such as TRA and TAM) advocate for studying and eliciting the perception for each innovation separately in the search for key drivers. IDT claims that the five major perceived characteristics of an innovation serve as major drivers in the innovation adoption behavior. The major perceived attributes of an Innovation consist of: relative advantage (additional benefit over the current method), compatibility (with the current needs and systems), complexity (of using the innovation), observability (visibility of result of innovation), and Trial-ability (possibility of experimenting with the innovation to a limited extend). These factors serve as the major determinants in individual's perception and are claimed to explain around half of the variance in the rate of innovation adoption [183]. Based on IDT, the other four categories of variables that determine the rate of adoptions are: Type of InnovationDecision (whether the adoption is optional, collective, or mandatory), Communication Channels (such as mass media), Nature of Social System (e.g. norms) and Extent of Change Agents' Promotion Efforts (effort made to promote the innovation).

\section{2) Concepts}

\section{Relative advantage}

The degree to which the new innovation is more advantageous than the state of the art. Relative advantage correlates with the rate of innovation adoption.

\section{Compatibility}

The degree to which the innovation is aligned with the existing values, systems and experiences as well as users' needs. Compatibility correlates with the rate of innovation adoption.

\section{Complexity}

Is the reciprocal value of the Perceived Ease of Use (as described in 3.1.2), the degree of effort required for learning how to use the new innovation. Complexity negatively correlates with the rate of innovation adoption.

\section{Trialability}

Is the degree to which the innovation can be tried out and experimented. This factor correlates with the rate of innovation adoption.

\section{Observability}

Is the degree to which the outcome of the innovation can be observed by other people. This visibility correlates with the rate of innovation adoption.

\section{3) Application and Extension}

Moore and Benbasat adapted IDT to study Information Technology systems. They adopted a set of concepts that they found best to measure users' perceptions of information technology innovation adoption [17]. The earlier theories in this report (such as TRA and TAM) suppose intention to be the direct antecedent that determines the adoption behavior as well as future usage. However, IDT is not concerned with the intention. Additionally, it emphasizes on the fact that the short-term and long-term adoption are different behaviors. This is particularly important in HTA, as it could explain the gap between the promised technology advantages and failure in delivering those long-term benefits. IDT explains how in technology adoption process, different outcomes from initial decision to use, to the continuous long term adoption of the innovation is possible through the changing perception of the user [185].

Cain and Mittman in their study of diffusion of innovation in Health Care, using IDT, developed a series of lesson plans for technology diffusion. Some of those lessons are including: Understand current behaviors and values; Innovations that reduce hassles are more likely to be successful; Mimic things from other parts of life; Look for opportunities to plug and play; Look for leapfrogging technology [186].

Many studies have integrated IDT with other proven theories like TAM. Lee et al. combined Innovation Diffusion Theory with TAM to investigate factors influencing employee's intention to use e-Learning systems in Taiwan. They identified compatibility, complexity, relative advantage, and trialability factors significant in forming the perceived usefulness; and complexity, relative advantage and trialability influential driver in perceived ease of use. Their study found the integrated model to be more powerful in planning, evaluation and execution of intervention plans [187].

To study nurses' adoption of medical e-Logistics, Tung et al. also integrated IDT with TAM and added two additional concepts of 'trust' and 'perceived financial cost'. The causal model of their proposed hybrid TAM was evaluated using structural equation modeling, and the findings suggested that 
'compatibility', 'perceived usefulness', 'perceived ease of use', and 'trust' all significantly influence 'behavioral intention to use'; and 'perceived financial cost' negatively impact behavioral intention to use [188]. Additionally, Chen et al. examination of factors increasing adoption of smartphone among healthcare professionals in US And Taiwan, also integrated TAM with IDT and added selfefficacy. They identified attitude and self-efficacy to directly and perceived usefulness and task relatedness indirectly influence the intention to use a smartphone. The findings suggest future smartphone applications and software programs to target those needs of health professionals [189].

Karsh et al. integrated three theories of TAM, IDT and STS (Sociotechnical Systems Theory [190]) to study the design of a highly adoptable medical error reporting system in three levels. The combined model was highly predictive and suggested that theories such as IDT and TAM can benefit from additional factors such as user-related punishment (introduced by STS). (As a side note, Sociotechnical Systems Theory does not focus on the adoption; it rather targets achieving higher optimizations through designing organizations based on better relationships of socio and technical elements that leads to more efficiency and higher quality of life.) The study also showed that none of the theories by themselves could account for the findings and they emphasized on the need for more comprehensive, detailed theory of technology implementation [191]. IDT has also been influential in extending other theories in the study of technology adoption [192].

\section{4) Evaluation}

IDT provides a holistic look at technology adoption from the market perspective. Instead of studying the intention, IDT theorize what it takes to directly influence the rate of adoption behavior. These factors are including perceived attributes of the innovation, characteristics of the adopters and ways those potential users learn and persuade the adoption (including the extent to which change agents and external forces make efforts toward the diffusion) [184]. While this inclusion provides a full view of the overall market adoption of independent-use innovations (and individual adoption), the theory is less conclusive in the studies of multi-user technologies (which are often the characteristics of health technologies) [193]. Additionally, in accordance with the criteria set in this paper as the yardstick for measuring the theory's qualification for HTA research, IDT does not qualify as described below.

Emotional influences, Value sensitivity, Demographic sensitivity, Time sensitivity: IDT's capacity of considering time variance and differentiating between initial technology acceptance and long-term diffusion is advantageous. However, it fails to consider either the emotional or the demographic characteristics significant in predicting technology adoption in healthcare. While the consideration of perception is advantageous in that the value sensitivity outside the rational cost benefit analysis can be explained, the theory as is does not provide the granularity needed for HTA studies [193].

Volitional and self-efficacy: IDT lack of attention to the self-efficacy is another shortcoming of the theory for HTA researches that has led to the addition of this factor to the theory in many studies of technology adoption [194] and HTA [189].

Practicality: IDT's attention to the social system, as a key determinant in healthcare, is favorable. IDT, with its inclusive consideration of what it takes to diffuse an innovation, provides a practical market oriented innovation adoption theory. However the theory is too limited by nature to meet the requirements for conducting empirical studies of innovation adoption in the complex multifaceted domain of healthcare [193]. This is more than evident by lack of HTA studies in literature solely based on IDT, and the abundance of researches that have integrated IDT with other theories like TAM and or TPB [187], [190], [195] and often supplemented by factors [188], [189] salient in driving the adoption in healthcare settings.

\section{Combined TAM and TPB (C-TAM-TPB) and TAM2}

Here two of the TAM extended theories: C-TAM-TPB and TAM2, as less significant yet influential in the body and evolution of technology adoption theories are briefly described and evaluated.

\section{1) Overview}

Taylor and Todd developed Combined TAM-TPB (also known as C-TAM-TPB or Augmented TAM) in 1995 in their search for a model that could better explain and predict information technology usage [131]. In C-TAM-TPB, TAM's two main constructs of perceived usefulness and perceived ease of use are considered the independent variables that influence the Attitude in driving behavioral intention (the dependent variable of TPB). Taylor and Todd study suggests that this model can better predict the information technology acceptance and provide more insight for IT product development [131]. Additionally their other studies showed that decomposing salient drivers of an application, in the theory could facilitate better predictability [196].

Venkatesh and Davis further extended TAM to TAM2 in 2000 [197]. In this model, perceived usefulness is considered as the dependent variables drived by different social and cognitive factors. Social factors consist of social norm and image and the cognitive constructs include job relevance, output quality, result demonstrability and perceived ease of use. In this model, subjective norm is the key factor that not only influences perceived usefulness and Image but also directly drives intention to use. While experience and voluntariness moderate the influence of subjective norm on intention to use (as well as subjective norm to perceived usefulness), all the other additional constructs (image, job relevance, output quality and result demonstrability) mainly influence perceived usefulness [197]. 


\section{2) Concepts}

As these constructs have been described earlier, only the list is provided as below.

\section{Combined TAM-TPB \\ Perceived Usefulness \\ Perceived Ease of Use \\ Attitude \\ Subjective Norm \\ Perceived Behavioral Control}

TAM2

Perceived Usefulness
Perceived Ease of Use
Subjective Norm
Image
Job Relevance
Output Quality
Result Demonstrability
Experience
Voluntariness

\section{3) Application and Extension}

Nkenke et al. used C-TAM-TPB to study the acceptance of virtual dental implant planning software in a dental school in Germany. Their research suggested acceptance of the system by the dental students due to the strong perception of its usefulness and students' positive attitude toward using it. The implication was that upon implementation, the supervisor should highlight the usefulness of the system which in turn will positively influence students' attitude toward usage [198].

TAM2 studies provided more inclusive look into technology acceptance by incorporating more granularity including the social factors [199]. Wu and Wang integrated TAM2 with IDT and added factors like risk and cost to study the adoption of mobile commerce where they found compatibility to be the most significant driver of the adoption behavior, among their target users [200]. Venkatesh and Davis [197] tested TAM2 in four different longitudinal field studies involving both voluntary and mandatory usage cases. The result validated the efficacy of TAM2 as the model explained 40 to 60 percent of the variance in perceived usefulness and 34 to 52 percent of the variance in intention to use. The longitudinal test in four organization found job relevance, output quality, result demonstrability, and perceived ease of use to significantly drive user acceptance.

\section{4) Evaluation}

Emotional influences, Value sensitivity, Demographic sensitivity, Volitional and self-efficacy, Time sensitivity: In both cases the salient factors have been decomposed to better explain and predict the technology acceptance. While in C-TAM-TPB the two salient factors of TAM contribute to incorporating major drivers of the attitudes toward technology adoption, and potentially making the theory more relevant to technology related behavior, there is no modification to make the theory more relevant to technology adoption in healthcare environment as neither emotional nor demographic factors have made it to this theory. Similarly in TAM2, despite the more sophisticated integration of factors and inclusion of volitional and social drivers, can't be considered a practical theory for such applications as it is still missing the factors describing demographics or emotional drivers key in health applications. While many studies of TAM and TAM2 find them useful [199], [200], findings repeatedly suggested [201] that integration into a broader model including the adoption drivers in human and the social change processes, provides better empirical models.

Practicality: Whether underutilization of these two theories is due to their short-lived time before the advent of UTAUT or lack of practicality, in that they were still missing some significant drivers in the study of adoption (as many studies had to supplement the theory with more concepts or theories [200], [201]), their popularity are by far less than their parent theories (TAM and TPB).

Analysis of C-TAM-TPB and TAM2, displays how the test of time has evolved TAM and TPB toward better technology adoption theories [198], [202] and how these theories have served as stepping-stones for grounding more comprehensive theories in technology adoption. In fact their roles in theorizing UTAUT are their most significant accomplishments. The citation to both combined TAM and TPB model (C-TAM-TPB) and TAM2 are hardly on their utilization and rather overwhelmingly related to their contributions in grounding UTAUT theory (described in the next section).

\section{E. Unified Theory of Acceptance and Use of Technology (UTAUT)}

1) Overview

UTAUT [203] integrates and theorizes the findings of eight theoretical models with the goal of constructing a unified technology acceptance theory that best explain the intention to use behavior. The constructing theories are Social Cognitive Theory (SCT), Theory of Reasoned Action (TRA), Theory of Planned Behavior (TPB), Technology Acceptance Model (TAM), TAM2, Innovation Diffusion Theory (IDT), Motivational Model (MM) and Model of PC Utilization (MPCU), which have all been explained in detail earlier.

The models put forward between two to seven factors of acceptance. From these factors, four (performance expectancy, effort expectancy, social influence and facilitation conditions) were identified as significant and became part of the model and three (anxiety, self-efficacy and attitude toward technology usage) were not identified as direct determinants. UTAUT as depicted in Figure 8, theorizes that performance expectancy, effort expectancy and social influence directly influence behavior intention and facilitating conditions as the independent drivers of technology adoption. Mediating factors of age, gender, 
voluntariness of use and experience are variables that moderate these influences.

Venkatesh et al. research in six different organizations validates the superiority of UTAUT in the prediction of technology usage [203]. In those studies UTAUT accounted for $70 \%$ of the variance of user behavior of technologies adoption. This is a substantial improvement over the founding 8 theories. Venkatesh et al. argue that this predictability might be the practical limits of our ability to explain individual acceptance and usage decisions [203].

\section{2) Concepts}

\section{Performance Expectancy}

Is the degree in which the user perceives the use of technology will help in the job performance. Research suggests that the influence of performance expectancy on intention to use technology is positive and that it is moderated by user's age and gender. Studies show that performance expectancy is the primary determinant in Information system acceptance among male and younger users [60]-[62].

\section{Effort Expectancy}

Is the level of effort user believes that have to put in to be able to successfully use the system. The research shows that age, and gender as well as level of experience mediate the influence of effort expectancy on the intention to use the technology. Literature suggests that effort expectancy is a more salient driver among female [61], and elderly [59] as well as those with low level of experience [196].

\section{Social Influence}

Adapted from the concept of social norm in TRA and $\mathrm{TPB}$, social influence is what user perceives from important people to her/him in considering whether she/he should be accepting the technology. Literature suggests a rather complicated relation in regards to this construct with all the moderating variables affecting the influence.

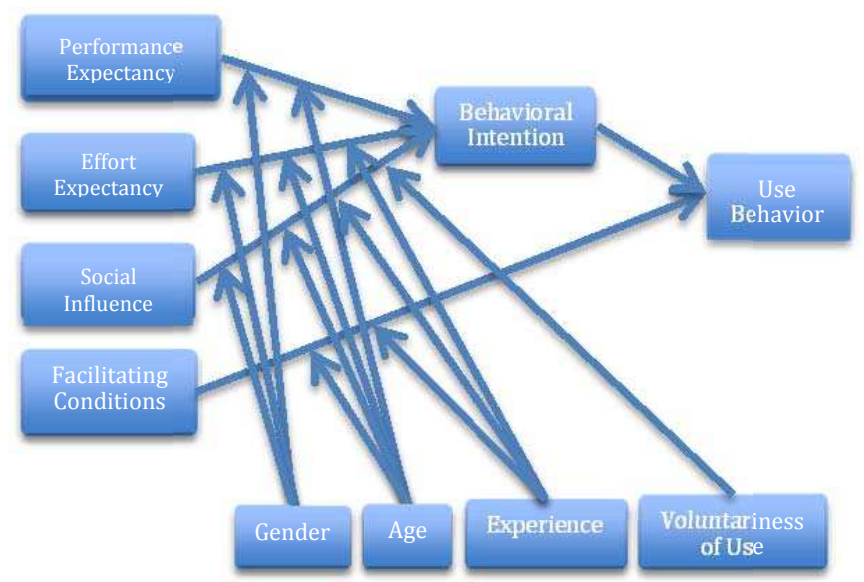

Figure 8 - Unified Theory of Acceptance and Use of Technology (UTAUT) [203]

\section{Facilitating Conditions}

Is the level of support the user perceives that the organization provides as part of the adoption/acceptance process for the new technology system. These could include providing system training, support staff, etc. Facilitating condition positively influences the actual system usage. This relation is moderated by experience and age.

The authors maintain that when both performance expectancy and effort expectancy constructs are satisfied, facilitating conditions becomes non-significant in predicting intention. Also, when moderated by experience and age, facilitating conditions will have a significant influence on usage behavior.

\section{Age, Gender, Experience, Voluntariness of use}

Are the factors moderating the influence of the above factors in use intention and behavior.

\section{3) Application and Extension}

UTAUT although appeared to be very popular (with over 9,580 citation of the originating publication [203] at the time of this report), its application has not become widely prevalent [178]. Prior to the existence of UTAUT, TAM was the most widely utilized theory to study IS/IT [204], [205], [206]. While the application of UTAUT in HTA is showing some momentum [208], [209] they are still scarce compared to the theory's popularity [204], [205], [206]. UTAUT has been applied to study the adoption and acceptance of technological innovations in fields such as communication innovations [209], online applications [210], and healthcare [208], [209].

Many of the HTA studies points out the need for integrating UTAUT with other theories and constructs to include a more inclusive picture of healthcare applications [179], [209]. Aggelidis and Chatzoglou to study technology acceptance in hospital, integrated UTAUT with the original TAM and added constructs to allow analysis of three contexts of (a) individual, (b) technological, and (c) implementation. Their results indicate that perceived usefulness, ease of use, social influence, attitude, facilitating conditions and selfefficacy significantly affects hospital personnel behavioral intention [208].

Duyck et al. applied UTAUT to assess staff user acceptance of PACS (a picture archiving and communication system) in the radiology department in a Belgium hospital. They found UTAUT as an adequate model for studying technology acceptance in radiology settings. While technical staffs like radiologists' and technologists,' attitude were positive and their intentions to use PACS were measured high, the other staffs' acceptance intention were influenced by their perceived usefulness of PACS. Facilitating Conditions in the form of support was also measured significant for the latter group's adoption intention [211].

Alikilic and Atabek studied PR professional acceptance of social media in Turkey. They identified much enthusiasm among them in using the technology to effectively 
communicate with customers and stakeholders without the need of intermediaries [212]. Similarly Curtis et al. studied the adoption of social media for pubic relation of non-profit organizations. They identified a significant correlation between credibility and UTAUT factors, indicating that PR practitioners are more likely to use social media if they perceive it as credible [213].

\section{4) Evaluation}

UTAUT is considered yet another leap forward in understanding technology acceptance, beating the predictability of TAM as the most popular [178] former theory [203]. Through evolution and by utilization of the learnings of the eight founding theories as well as the experiences of abundant related studies and applications, UTAUT, compared to its former theories, provides a promising theoretical base for the study of the technology adoption. While almost all the studies and applications of UTAUT have found the theory potent in capturing salient drivers influencing technology adoption [214]-[216], its sufficiency is under much debate [23], [178], [217]. Similar to the criticism of TAM's parsimony, where many external factors found affecting the main concepts needed to be added [174], UTAUT has hardly been used as is and without the need for addition of factors. To model adoption behavior, many studies using UTAUT, changed the theory [208], integrated with other theories [98] and most of them added concepts missing [23], [208], [209], [214], [218], [219].

UTAUT's actual utilization is much less than it appears. A 2011 systematic review of articles that cited UTAUT, found that most of the references were in relation to the general context of adoption theory evolution, and only less than $4 \%$ of those articles actually reported the full use of the theory [178]. While there is a general consensus on, and admiration for TAM's (as the founding theory of UTAUT) remarkable performance in empirical researches, these theories have also become the target of much criticism [23], [134], [220]-[222]. The overarching argument is that these approaches' parsimonious property oversimplifies the process of decision-making and dismisses many factors and steps. These include the underlying factors driving determinants like performance expectancy/perceived usefulness and effort expectancy/ease of use as well as factors and steps involved between intention and actual behavior. Van Raaij and Schepers posit that UTAUT has integrated a diverse set of dissimilar factors into a single psychometric construct. They argue that the high predictability of UTAUT is only feasible when moderating the entire key drives' relationships with up to four variables (age, gender, experience and voluntariness) to allow for higher coefficients. Since this condition not always presents itself (including in their case), they didn't base their study of online learning in China based on UTAUT [223]. Additionally, Bagozzi claims UTAUT to be a parsimonious mishmash of many uncoordinated summary of earlier theories [23]. And in his evaluation, complains about lack of theoretical development in the field of technology adoption as he states:

'... little methodological pluralism exists in the information system area... It is no wonder then that theories and knowledge evolve so narrowly in fields, and coupled with the inevitable conflicts, censorship, and gate-keeper effects all fields undergo in the review process, we see a reluctance to discard that which has grown stale, to borrow knowledge from other areas, and to be open to new ideas within our own fields.' [23]

In regards to the criteria identified earlier, the following evaluation points out UTAUT performance capacity for conducting HTA research.

Emotional influences: Although UTAUT doesn't explicitly capture HTA's significant emotional factors, the perceived notion of 'performance expectancy' and 'effort expectancy' factors partially encompass users' emotion (such as anxiety and playfulness) toward usefulness and ease of use. Additionally, the mediating factors of experience and voluntariness of use can, to a small degree, reflect the affect toward using technology.

Demographic sensitivity: UTAUT's capacity to allocate salient health demographic characteristics of age and gender as the moderating factors on the influence of key factors in the process of acceptance makes the theory valuable for such demographic sensitive studies like HTA.

Value sensitivity, Volitional and self-efficacy: There is no particular factor in the theory that highlights the importance of the quality of one's healthcare decision. Moreover, as many studies using UTAUT had to enhance the model by adding it back as an external factor [208], [209], exclusion of self-efficacy decreases the potency to explain HTA behaviors.

Time sensitivity: The inclusion of experience can account for time sensitivity of the theory. A study of UTAUT suggests that while the theory is explaining intention to use technology, it can also predicts future adoption behavior [216]. The study also calls out for the organizations to be aware of this significant advantage and to use theoretical based research prior to making major investment in future healthcare technology [216].

Practicality: Whether UTAUT is found too parsimonious [23], [178], [220] or too crowded [223], and regardless of its use as the sole theoretical source for HTA studie, or part of a bigger integrated model combined with other theories and external variables, the literature supports its practicality in conducting technology adoption researches in general adoption studies, as well as HTA. While the claim of UTAUT's 70\% predictability excites anyone conducting technology adoption research, this performance does not appear to be guaranteed in every application [223]. And, there is overwhelming evidence [178], [208], [209], [214], [218], [219] of the growing needs for the theories to be supplemented and integrated with the salient factors for 
specific applications to facilitate creation of more realistic models of drivers of the adoption behavior in the complex healthcare settings.

\section{DISCUSSION}

Many research findings emphasize the importance of basing the study of behavior on well-tested theories to avoid reinventing the wheel [141], while testing their appropriateness, through a rigorous evaluation process, and if needed, changing the theories, or creating new ones [23], [134], [191]. Eleven popular social cognitive theories, from the most general to the most innovation oriented, was reviewed and evaluated for their ability to understand, predict and or intervene in health technology usage. Many applications of these theories particularly in the healthcare space were studied, which led to the overall observation that although none is perfect, by and large, all these theories were successful in facilitating the creation of appropriate models leading to realistic prediction of users intention and behavior. This finding reaffirmed the importance of theoretical knowledge as the foundation for conducting technology adoption research.

Some of these theories were more potent and provided a higher predictability; in particular TAM has had a remarkable performance [23], [178], UTAUT looks promising [203], [223], and RAA with its inclusiveness of driving factors makes a powerful theory [113], [143], [224]. However this review of the most popular social cognitive theories prevalent in technology adoption research, could not find an ideal theory for conducting health technology adoption research. While RAA provides more holistic representation of the factors involved in HTA behavior [33], [145], [145] it is still not ideal as it encompasses drivers such as emotion and demographic characteristics only as background influence. This can relegate the influence of those factors on the intention to use [144]. Furthermore, UTAUT is another generally successful model [197]. With its minimum set of constructs that have been extracted from earlier validated theories, it can guide a model creation that arguably captures most important factors in studying technology acceptance identified over the past four decades [203]. Nonetheless, UTAUT's lack of sensitivity to the emotional drivers, salient in healthcare, needs to be taken into consideration. While the need for addition of concepts significant in HTA is not unique to UTAUT [225], it is the recurring theme of studies utilizing this theory. To improve the model based on UTAUT researchers more than often had to add many external factors salient in the studied applications [178], [208], [209], [214], [218], [226].

Visiting some of the challenges in the study of technology adoption/acceptance in healthcare, social influences [141], [159], emotional factors [38], [42] and demographic characteristics [60]-[62] (gender and age in particular) appear to be significant yet undermined drivers in the theories in this space. Many studies highlight the importance of integration of demographic characteristics in general and gender and age in particular for the effectiveness of the intervention plan [59], [224]. In the process of technology adoption in healthcare these determinants become key moderating factors that need to be considered. For example, while findings suggest that perceived usefulness is the most significant determinant among male population, perceived ease of use and social norms are the key drivers in determining intention to use in female and elderly [122], [169]. The other significant concept that an appropriate HTA theory should pay attention to and be able to guide modeling, is the differentiation of initial adoption versus long-term behavior. Identifying these differences are key in development of effective health behavior interventions.

To create a more holistic model and effective approach in health behavior intervention, addition of important concepts [98], [208], [219], and integration of more than one theory [98], [125] are the most popular approaches to overcome the current theoretical shortcomings. Integration approach has also been applied at the theoretical level where two or more theories are combined to provide a more comprehensive model (C-TAM-TPB [131], TAM2 [197], RAA [96]). This can provide a practical solution for addressing the needs in the health contexts where one theory can't provide a comprehensive picture of the influencing factors and the integrated theories can better facilitate model creation. However extra care and scrutiny is required as adding or removing extra factors or combining theories should only be done if improves the model [22]. Ajzen's criteria for adding predictors seem to be adequate in that the new factor, after existing ones have been taken to account, should provide a high share of variance [15].

The writings on the walls of literature are indicating the era of having one unified model that can generalize the technology acceptance across industries and applications might be over. The days where the major concern was the adoption of IT in organizations are gone, as not using them is becoming an unimaginable phenomenon. The study of applications of the reviewed theories reaffirms this, as general applications such as office systems' adoption studies, which consisted $27 \%$ of all TAM studies until 2003 [174], encompassed only $2.3 \%$ of studies using UTAUT until 2011 [178].

Literature presents a large body of studies in which theories have had to be merged, changed and or supplemented with external factors to create more realistic models reflecting the specifics of the adoption behavior being studied. Additionally the relationship among theoretical concepts found to be varied based on the behavior being researched [134]. The meta-analysis of 56 health behavior researches using TPB found that the theory's performance varies across different health applications as the mean correlation of the concepts changed according to the type of the health behavior being studied [123].

There are growing evidences in the literature [23], [123], [134], [222] as to the need for creating new behavior specific 
theories or creating extensions of the known ones that better explain the specifics of those particular applications (like the one created by Schaper and Pervan for information and communication technology acceptance among occupational therapists [176]). This will not only provide more information about the behavior being studied, it will also better guide the model creation leading to more effective intervention plans. This is also aligned with the empirical studies in the health applications as the examination of the usage of health behavior theories depicts a wide spectrum from theory simply informing the study to the study leading to theory creation [227].

Regardless of the theory, it is becoming evident that while the popularity of these theories are not the same; their characteristics have all stayed unchanged [228]. Rothman claims that innovation and advances in health behavior change will happen if interventions are used to test and refine theory; and asserts that theory should be: 'treated as a dynamic entity whose value depends on it being not only applied and tested rigorously, but also refined based on the findings afforded by those tests' [228]. This shortcoming is even more pressing for researches that have to apply the theoretical knowledge to the study of health technology adoption [134]; especially that theoretical development of technology adoption behavior (compared to the study of human behavior) is believed to be in its infancy [229]. To realize progress in health behavior theory development and modification, Head and Noar recommend developing theories that are informed by data and more effective for explaining, predicting and intervening health behavior [134]. In addition, Noar and Zimmerman warn that despite the amplitude of studies on health behavior we are not making major contribution to this area of the research [138]. Crosby and Noar also complain about the theory development being stalled compared to the evolution of the health practices [230].

Furthermore, the battle between generalizability and utility is a heated one. However, when it comes to empirical studies, many meta-analysis not only suggest that utility trumps generalizability [103], they highlight the need for creation of new theories that can better facilitate empirical studies and have passed rigorous evaluation [23], [230]. One last note to mention, is another fundamental issue with the current methods of studies' use of questionnaires that may change, as opposed to collect, people's thinking [22], [222]. To avoid the interference and presumption that obstruct the view to the mental model involved in the adoption decision making, the use of user centered inquiry methods like ethnography becomes important due to their nature of observation that avoids framing of the enquiry [231].

\section{CONCLUSION}

Comprehensive review of the popular social cognitive theories and their applications in health behavior reveals important information for consideration. Literature highlights the importance of basing empirical studies of human behavior toward health technology acceptance on appropriate proven theories to avoid reinventing the wheel. While there is no one-size-fits-all theoretical approach and most empirical studies end up adding and or decomposing one or many components of the theories, all theories are useful and some, such as RAA and UTAUT are better fit for facilitating the modeling of health technology adoption.

The overwhelming evidence in the literature highlights the problem of stalled theory development and the widening gap between theoretical advancement and the fast evolution of the health practices. There is a call to arms for the health researchers to treat theories as dynamic entities with the compelling need to actively 1) challenge and refine existing theories based on findings, and 2) form new theories tailored to specific health applications that have passed rigorous evaluations and better reflect empirical findings.

\section{REFERENCES}

[1] L. Li, "A Critical Review of Technology Acceptance Literature," Retrieved April, vol. 19, p. 2011, 2010.

[2] D. Tang and L. Chen, "A review of the evolution of research on information Technology Acceptance Model," in Business Management and Electronic Information (BMEI), 2011 International Conference on, 2011, vol. 2, pp. 588-591.

[3] D. Callahan, "health care costs and medical technology," Hastings Cent., 2008.

[4] R. E. Litan, "Vital signs via broadband: Remote health monitoring transmits savings, enhances lives," Better Health Care Together, 2008.

[5] R. Hillestad, J. Bigelow, A. Bower, F. Girosi, R. Meili, R. Scoville, and R. Taylor, "Can Electronic Medical Record Systems Transform Health Care? Potential Health Benefits, Savings, And Costs," Health Aff. (Millwood), vol. 24, no. 5, pp. 1103-1117, Sep. 2005.

[6] J. S. Ash, P. N. Gorman, V. Seshadri, and W. R. Hersh, "Computerized Physician Order Entry in U.S. Hospitals: Results of a 2002 Survey," J. Am. Med. Inform. Assoc., vol. 11, no. 2, pp. 95-99, Mar. 2004.

[7] "A Third of Consumers Who Bought Wearable Devices Have Ditched Them - Slashdot." [Online]. Available: http://mobile.slashdot.org/story/14/04/02/0426201/a-third-ofconsumers-who-bought-wearable-devices-have-ditched-them. [Accessed: 09-Oct-2014].

[8] D. Ledger and D. McCaffrey, "How the Science of Human Behavior Change Offers the Secret to Long-Term Engagement," Endeav. Partn. LLC, Jan. 2014.

[9] A. L. Kellermann and S. S. Jones, "What It Will Take To Achieve The As-Yet-Unfulfilled Promises Of Health Information Technology," Health Aff. (Millwood), vol. 32, no. 1, pp. 63-68, Jan. 2013.

[10] ASPA, "HHS.gov/Recovery." [Online]. Available: http://www.hhs.gov/recovery/. [Accessed: 14-Sep-2014].

[11] J. G. Anderson, "Social, ethical and legal barriers to E-health," Int. J. Med. Inf., vol. 76, no. 5-6, pp. 480-483, May 2007.

[12] M. Khosrowpour, Encyclopedia of information science and technology, vol. 1. IGI Global, 2005.

[13] B. H. Hall and B. Khan, "Adoption of New Technology," New Economy Handbook: Hall and Khan, 2002, p. 38.

[14] "Diffusion - Definition and More from the Free Merriam-Webster Dictionary." [Online]. Available: http://www.merriamwebster.com/dictionary/diffusion. [Accessed: 28-Oct-2014].

[15] I. Ajzen and M. Fishbein, "Questions Raised by a Reasoned Action Approach: Comment on Ogden (2003).," Health Psychol., vol. 23, no. 4, pp. 431-434, 2004. 
[16] E. M. Rogers, Diffusion of innovations. Simon and Schuster, 2010.

[17] G. C. Moore and I. Benbasat, "Integrating Diffusion of Innovations and Theory of Reasoned Action models to predict utilization of information technology by end-users," in Diffusion and Adoption of Information Technology, K. Kautz and J. Pries-Heje, Eds. Springer US, 1996, pp. 132-146.

[18] S. Ghoshal and C. A. Bartlett, "Creation, Adoption, and Diffusion of Innovations by Subsidiaries of Multinational Corporations," J. Int. Bus. Stud., vol. 19, no. 3, pp. 365-388, Oct. 1988.

[19] J. A. Norton and F. M. Bass, "A Diffusion Theory Model of Adoption and Substitution for Successive Generations of High-Technology Products," Manag. Sci., vol. 33, no. 9, pp. 1069-1086, Sep. 1987.

[20] "Adoption - Definition and More from the Free Merriam-Webster Dictionary." [Online]. Available: http://www.merriamwebster.com/dictionary/adoption. [Accessed: 13-Oct-2014].

[21] "Acceptance - Definition and More from the Free Merriam-Webster Dictionary." [Online]. Available: http://www.merriamwebster.com/dictionary/acceptance. [Accessed: 13-Oct-2014].

[22] S. Mohammadi and A. Kaldi, "Adoption of iris-based authentication," in Industrial Engineering and Engineering Management, 2008. IEEM 2008. IEEE International Conference on, 2008, pp. 1582-1586.

[23] R. P. Bagozzi, "The Legacy of the Technology Acceptance Model and a Proposal for a Paradigm Shift.," J. Assoc. Inf. Syst., vol. 8, no. 4, p. 3, 2007.

[24] P. J. Hu, P. Y. Chau, O. R. L. Sheng, and K. Y. Tam, "Examining the technology acceptance model using physician acceptance of telemedicine technology," J. Manag. Inf. Syst., vol. 16, no. 2, pp. 91$112,1999$.

[25] S. H. Kim, "Moderating effects of job relevance and experience on mobile wireless technology acceptance: Adoption of a smartphone by individuals," Inf. Manage., vol. 45, no. 6, pp. 387-393, 2008.

[26] P. Y. Chau and P. J.-H. Hu, "Information technology acceptance by individual professionals: A model comparison approach*," Decis. Sci., vol. 32, no. 4, pp. 699-719, 2001.

[27] P. J.-H. Hu, T. H. Clark, and W. W. Ma, "Examining technology acceptance by school teachers: a longitudinal study," Inf. Manage., vol. 41, no. 2, pp. 227-241, 2003.

[28] W. W. Ma, R. Andersson, and K.-O. Streith, "Examining user acceptance of computer technology: An empirical study of student teachers," J. Comput. Assist. Learn., vol. 21, no. 6, pp. 387-395, 2005.

[29] R. Agarwal and J. Prasad, "A conceptual and operational definition of personal innovativeness in the domain of information technology," Inf. Syst. Res., vol. 9, no. 2, pp. 204-215, 1998.

[30] B. . Zenobia and C. M. Weber, "Deciding to change: An event sequence analysis of consumer adoption behavior," in Portland International Conference on Management of Engineering Technology, 2009. PICMET 2009, 2009, pp. 2666-2676.

[31] B. A. Zenobia and C. M. Weber, "Opening the black box of technology adoption: The motive-technology-belief framework," Int. J. Innov. Technol. Manag., vol. 8, no. 04, pp. 535-555, 2011.

[32] K. Glanz and D. B. Bishop, "The role of behavioral science theory in development and implementation of public health interventions," Annu. Rev. Public Health, vol. 31, pp. 399-418, 2010.

[33] K. Glanz, B. K. Rimer, and K. Viswanath, Health behavior and health education: theory, research, and practice. John Wiley \& Sons, 2008.

[34] M. Fishbein, "A Reasoned Action Approach to Health Promotion," Med. Decis. Making, vol. 28, no. 6, pp. 834-844, Nov. 2008.

[35] R. Hillestad, J. Bigelow, A. Bower, F. Girosi, R. Meili, R. Scoville, and R. Taylor, "Can Electronic Medical Record Systems Transform Health Care? Potential Health Benefits, Savings, And Costs," Health Aff. (Millwood), vol. 24, no. 5, pp. 1103-1117, Sep. 2005.

[36] G. M. Hochbaum, J. R. Sorenson, and K. Lorig, "Theory in health education practice," Health Educ. Behav., vol. 19, no. 3, pp. 295-313, 1992.

[37] R. J. DiClemente, R. A. Crosby, and M. Kegler, Emerging theories in health promotion practice and research. John Wiley \& Sons, 2009.

[38] H. Baumgartner, R. Pieters, and R. P. Bagozzi, "Future-oriented emotions: conceptualization and behavioral effects," Eur. J. Soc. Psychol., vol. 38, no. 4, pp. 685-696, 2008.
[39] C. Flavián-Blanco, R. Gurrea-Sarasa, and C. Orús-Sanclemente, "Analyzing the emotional outcomes of the online search behavior with search engines," Comput. Hum. Behav., vol. 27, no. 1, pp. 540551, 2011.

[40] P. Harvey and L. M. Victoravich, "The Influence of Forward-Looking Antecedents, Uncertainty, and Anticipatory Emotions on Project Escalation*," Decis. Sci., vol. 40, no. 4, pp. 759-782, 2009.

[41] R. P. Bagozzi, M. Gopinath, and P. U. Nyer, "The role of emotions in marketing," J. Acad. Mark. Sci., vol. 27, no. 2, pp. 184-206, 1999.

[42] G. L. Clore and J. R. Huntsinger, "How emotions inform judgment and regulate thought," Trends Cogn. Sci., vol. 11, no. 9, pp. 393-399, 2007.

[43] G. F. Loewenstein, E. U. Weber, C. K. Hsee, and N. Welch, "Risk as feelings.," Psychol. Bull., vol. 127, no. 2, p. 267, 2001.

[44] V. Venkatesh, "Determinants of perceived ease of use: Integrating control, intrinsic motivation, and emotion into the technology acceptance model," Inf. Syst. Res., vol. 11, no. 4, pp. 342-365, 2000.

[45] A. Ortiz de Guinea and M. L. Markus, "Why break the habit of a lifetime? Rethinking the roles of intention, habit, and emotion in continuing information technology use," Manag. Inf. Syst. Q., vol. 33, no. 3, p. 3, 2009.

[46] D. G. Mick and S. Fournier, "Paradoxes of technology: consumer cognizance, emotions, and coping strategies," J. Consum. Res., vol. 25, no. 2, pp. 123-143, 1998.

[47] T. Hirsch, J. Forlizzi, E. Hyder, J. Goetz, C. Kurtz, and J. Stroback, "The ELDer project: social, emotional, and environmental factors in the design of eldercare technologies," in Proceedings on the 2000 conference on Universal Usability, 2000, pp. 72-79.

[48] M. Díaz, J. Saez-Pons, M. Heerink, and C. Angulo, "Emotional factors in robot-based assistive services for elderly at home," in $R O$ MAN, 2013 IEEE, 2013, pp. 711-716.

[49] M. R. Simonson, M. Maurer, M. Montag-Torardi, and M. Whitaker, "Development of a standardized test of computer literacy and a computer anxiety index," J. Educ. Comput. Res., vol. 3, no. 2, pp. 231-247, 1987.

[50] K. V. Wild, N. C. Mattek, S. A. Maxwell, H. H. Dodge, H. B. Jimison, and J. A. Kaye, "Computer-related self-efficacy and anxiety in older adults with and without mild cognitive impairment," Alzheimers Dement., vol. 8, no. 6, pp. 544-552, Nov. 2012.

[51] J. Webster and J. J. Martocchio, "Microcomputer playfulness: development of a measure with workplace implications," $M I S Q$., pp. 201-226, 1992.

[52] V. Venkatesh, "Determinants of perceived ease of use: Integrating control, intrinsic motivation, and emotion into the technology acceptance model," Inf. Syst. Res., vol. 11, no. 4, pp. 342-365, 2000.

[53] R. P. Bagozzi, M. Gopinath, and P. U. Nyer, "The role of emotions in marketing," J. Acad. Mark. Sci., vol. 27, no. 2, pp. 184-206, 1999.

[54] E. D. Frohlich, "Life's quality: a major consideration in health care delivery--especially with hypertensive diseases," Cardiovasc. Drugs Ther. Spons. Int. Soc. Cardiovasc. Pharmacother., vol. 3, no. 6, pp. 821-823, Dec. 1989.

[55] N. Rahimi, M. Nickeson, and P. Ghafoori, "Assessing Technologies for Post Discharge Follow-up of Orthopedic Surgery," in Infrastructure and Service Integration (PICMET), 2014 Proceedings of PICMET'14:, 2014.

[56] H.-G. Eichler, S. X. Kong, W. C. Gerth, P. Mavros, and B. Jönsson, "Use of Cost-Effectiveness Analysis in Health-Care Resource Allocation Decision-Making: How Are Cost-Effectiveness Thresholds Expected to Emerge?," Value Health, vol. 7, no. 5, pp. 518-528, 2004.

[57] E. L. Abramson, S. McGinnis, J. Moore, R. Kaushal, and HITEC investigators, "A statewide assessment of electronic health record adoption and health information exchange among nursing homes," Health Serv. Res., vol. 49, no. 1 Pt 2, pp. 361-372, Feb. 2014.

[58] L. Thomas, L. Little, P. Briggs, L. McInnes, E. Jones, and J. Nicholson, "Location tracking: views from the older adult population," Age Ageing, vol. 42, no. 6, pp. 758-763, Nov. 2013.

[59] K. V. Wild, N. C. Mattek, S. A. Maxwell, H. H. Dodge, H. B. Jimison, and J. A. Kaye, "Computer-related self-efficacy and anxiety 
in older adults with and without mild cognitive impairment," Alzheimers Dement., vol. 8, no. 6, pp. 544-552, 2012.

[60] V. Venkatesh, M. G. Morris, and P. L. Ackerman, "A longitudinal field investigation of gender differences in individual technology adoption decision-making processes," Organ. Behav. Hum. Decis. Process., vol. 83, no. 1, pp. 33-60, 2000.

[61] W. Wilkowska, S. Gaul, and M. Ziefle, A Small but Significant Difference-The Role of Gender on Acceptance of Medical Assistive Technologies. Springer, 2010.

[62] A. K. Schaar and M. Ziefle, "Smart clothing: Perceived benefits vs. perceived fears," in Pervasive Computing Technologies for Healthcare (PervasiveHealth), 2011 5th International Conference on, 2011, pp. 601-608.

[63] M. Powell and D. Ansic, "Gender differences in risk behaviour in financial decision-making: An experimental analysis," J. Econ. Psychol., vol. 18, no. 6, pp. 605-628, 1997.

[64] J. A. Talaga and T. A. Beehr, "Are there gender differences in predicting retirement decisions?," J. Appl. Psychol., vol. 80, no. 1, p. 16, 1995.

[65] T. M. Steffen and P. C. Nystrom, "Problem solving by hospital managers," Health Care Manage. Rev., vol. 13, no. 4, pp. 25-31, 1988.

[66] C. J. Armitage and M. Conner, "Efficacy of the theory of planned behaviour: A meta-analytic review," Br. J. Soc. Psychol., vol. 40, no. 4, pp. 471-499, 2001.

[67] M. Conner and P. Norman, Predicting health behaviour. McGrawHill International, 2005.

[68] A. Bandura, "Social cognitive theory: An agentic perspective," Annu. Rev. Psychol., vol. 52, no. 1, pp. 1-26, 2001.

[69] C. O. Seneler, N. Basoglu, and T. U. Daim, "An empirical analysis of the antecedents of adoption of online services: A prototype-based framework," J. Enterp. Inf. Manag., vol. 23, no. 4, pp. 417-438, 2010.

[70] K. Laver, S. George, J. Ratcliffe, and M. Crotty, "Measuring technology self efficacy: reliability and construct validity of a modified computer self efficacy scale in a clinical rehabilitation setting," Disabil. Rehabil., vol. 34, no. 3, pp. 220-227, Dec. 2011.

[71] D. I. Ivanov, "Ensuring Long-Term Adoption of Technology: Mandated Use and Individual Habit as Factors that Establish Technology into Healthcare Practice," Case Western Reserve University, 2008.

[72] E. Karahanna, D. W. Straub, and N. L. Chervany, "Information Technology Adoption Across Time: A Cross-Sectional Comparison of Pre-Adoption and Post-Adoption Beliefs," MIS Q., vol. 23, no. 2, pp. 183-213, Jun. 1999.

[73] F. N. Kerlinger and H. B. Lee, Foundations of behavioral research: Educational and psychological inquiry. Holt, Rinehart and Winston New York, 1964.

[74] A. Bandura, Social foundations of thought and action. Englewood Cliffs, NJ Prentice Hall., 1986.

[75] D. H. Schunk, "Social Cognitive Theory and Self-Regulated Learning," in Self-Regulated Learning and Academic Achievement, B. J. Zimmerman and D. H. Schunk, Eds. Springer New York, 1989, pp. 83-110.

[76] D. K. Ehlers and J. Huberty, "Middle-Aged Women's Preferred Theory-Based Features in Mobile Physical Activity Applications," $J$. Phys. Act. Health, Dec. 2013.

[77] J. Dollard and N. E. Miller, "Personality and psychotherapy; an analysis in terms of learning, thinking, and culture.," 1950.

[78] J. A. Bargh and E. Morsella, "The Unconscious Mind," Perspect. Psychol. Sci. J. Assoc. Psychol. Sci., vol. 3, no. 1, pp. 73-79, Jan. 2008.

[79] A. Samoilov and M. R. Goldfried, "Role of Emotion in CognitiveBehavior Therapy," Clin. Psychol. Sci. Pract., vol. 7, no. 4, pp. 373$385,2000$.

[80] "The Social Cognitive Theory." [Online]. Available: http://sphweb.bumc.bu.edu/otlt/MPH-Modules/SB/SB721Models/SB721-Models5.html. [Accessed: 17-Aug-2014].

[81] A. Bandura, Self-efficacy. Wiley Online Library, 1994.

[82] A. Bandura, "Self-efficacy mechanism in human agency.," Am. Psychol., vol. 37, no. 2, p. 122, 1982.
[83] "Exercise Psychology Laboratory - Measures: Exercise Self-Efficacy Scale (EXSE)." [Online]. Available: http://epl.illinois.edu/meas_exse.html. [Accessed: 16-Aug-2014].

[84] S. Pourrazavi, H. Allahverdipour, M. A. Jafarabadi, and H. Matlabi, "A socio-cognitive inquiry of excessive mobile phone use," Asian $J$. Psychiatry, 2014.

[85] R. Agarwal, C. Anderson, J. Zarate, and C. Ward, "If we offer it, will they accept? Factors affecting patient use intentions of personal health records and secure messaging," J. Med. Internet Res., vol. 15, no. 2, 2013.

[86] R. Schwarzer and R. Fuchs, "Self-efficacy and health behaviours," Predict. Health Behav., pp. 163-196, 1996.

[87] A. Bandura, "Influence of models' reinforcement contingencies on the acquisition of imitative responses.," J. Pers. Soc. Psychol., vol. 1, no. 6, p. 589, 1965.

[88] A. Bandura, "Health promotion by social cognitive means," Health Educ. Behav., vol. 31, no. 2, pp. 143-164, 2004.

[89] S. M. Miller, Y. Shoda, and K. Hurley, "Applying cognitive-social theory to health-protective behavior: breast self-examination in cancer screening.," Psychol. Bull., vol. 119, no. 1, p. 70, 1996.

[90] J. T. Tufano and B. T. Karras, "Mobile eHealth interventions for obesity: a timely opportunity to leverage convergence trends," J. Med. Internet Res., vol. 7, no. 5, 2005.

[91] Everett M. Rogers Award Colloquium 2007. 2007.

[92] A. Bandura, "Health promotion from the perspective of social cognitive theory," Psychol. Health, vol. 13, no. 4, pp. 623-649, Jul. 1998.

[93] R. Wood and A. Bandura, "Social cognitive theory of organizational management," Acad. Manage. Rev., vol. 14, no. 3, pp. 361-384, 1989.

[94] M. E. Fishbein, "Readings in attitude theory and measurement.," 1967.

[95] M. Fishbein and I. Ajzen, Belief, attitude, intention and behavior: An introduction to theory and research. 1975.

[96] M. Fishbein and I. Ajzen, Predicting and changing behavior: The reasoned action approach. Taylor \& Francis, 2011.

[97] P. L. Prin and M. E. Mills, "Nurses' MEDLINE usage and research utilization," Stud. Health Technol. Inform., vol. 46, pp. 451-456, 1997.

[98] G. A. Samoutis, E. S. Soteriades, H. E. Stoffers, T. Zachariadou, A. Philalithis, and C. Lionis, "Designing a multifaceted quality improvement intervention in primary care in a country where general practice is seeking recognition: the case of Cyprus," BMC Health Serv. Res., vol. 8, p. 181, 2008.

[99] M. Fishbein and S. E. Middlestadt, "Using the theory of reasoned action as a framework for understanding and changing AIDS-related behaviors," in Primary prevention of AIDS: Psychological approaches, V. M. Mays, G. W. Albee, and S. F. Schneider, Eds. Thousand Oaks, CA, US: Sage Publications, Inc, 1989, pp. 93-110.

[100] E. Y. M. Cheung and J. Sachs, "TEST OF THE TECHNOLOGY ACCEPTANCE MODEL FOR A WEB-BASED INFORMATION SYSTEM IN A HONG KONG CHINESE SAMPLE 1," Psychol. Rep., vol. 99, no. 3, pp. 691-703, 2006.

[101] X. Zhang, X. Guo, K.-H. Lai, F. Guo, and C. Li, "Understanding gender differences in m-health adoption: a modified theory of reasoned action model," Telemed. J. E-Health Off. J. Am. Telemed. Assoc., vol. 20, no. 1, pp. 39-46, Jan. 2014.

[102] B. H. Sheppard, J. Hartwick, and P. R. Warshaw, "The theory of reasoned action: A meta-analysis of past research with recommendations for modifications and future research," J. Consum. Res., pp. 325-343, 1988.

[103] A. F. Chalmers (Alan Francis), What is this thing called science? : an assessment of the nature and status of science and its methods, 2nd ed.. StLucia, Qld: University of Queensland Press, 1982.

[104] T. A. Shimp and A. Kavas, "The theory of reasoned action applied to coupon usage," J. Consum. Res., pp. 795-809, 1984.

[105] R. P. Bagozzi, "Attitudes, intentions, and behavior: A test of some key hypotheses.," J. Pers. Soc. Psychol., vol. 41, no. 4, p. 607, 1981.

[106] R. P. Bagozzi, "A field investigation of causal relations among cognitions, affect, intentions, and behavior," J. Mark. Res., pp. 562583,1982 . 
[107] M. J. Ryan, "Behavioral intention formation: the interdependency of attitudinal and social influence variables," J. Consum. Res., pp. $263-$ $278,1982$.

[108] I. Ajzen, "From Intentions to Actions: A Theory of Planned Behavior," in Action Control, P. D. J. Kuhl and D. J. Beckmann, Eds. Springer Berlin Heidelberg, 1985, pp. 11-39.

[109] I. Ajzen, "The theory of planned behavior," Organ. Behav. Hum. Decis. Process., vol. 50, no. 2, pp. 179-211, Dec. 1991.

[110] I. Ajzen, "Theory of planned behavior," Handb Theor Soc Psychol Vol One, vol. 1, p. 438, 2011.

[111] I. Ajzen, "Attitude structure and behavior," Attitude Struct. Funct., pp. 241-274, 1989

[112] M. Fishbein, "The role of theory in HIV prevention," AIDS Care, vol. 12, no. 3, pp. 273-278, 2000.

[113] S. J. Sweitzer, M. E. Briley, C. Roberts-Gray, D. M. Hoelscher, R. B. Harrist, D. M. Staskel, and F. D. Almansour, "Lunch Is In The Bag: Increasing Fruits, Vegetables, and Whole Grains in Sack Lunches of Preschool-Aged Children," J. Am. Diet. Assoc., vol. 110, no. 7, pp. 1058-1064, Jul. 2010.

[114] K. Chase, M. Reicks, and J. M. Jones, "Applying the theory of planned behavior to promotion of whole-grain foods by dietitians," $J$. Am. Diet. Assoc., vol. 103, no. 12, pp. 1639-1642, 2003.

[115] A. McConnon, M. Raats, A. Astrup, M. Bajzová, T. HandjievaDarlenska, A. K. Lindroos, J. A. Martinez, T. M. Larson, A. Papadaki, A. Pfeiffer, and others, "Application of the Theory of Planned Behaviour to weight control in an overweight cohort. Results from a pan-European dietary intervention trial (DiOGenes)," Appetite, vol. 58, no. 1, pp. 313-318, 2012.

[116] R. E. Rhodes and K. S. Courneya, "Investigating multiple components of attitude, subjective norm, and perceived control: An examination of the theory of planned behaviour in the exercise domain," Br. J. Soc. Psychol., vol. 42, no. 1, pp. 129-146, 2003.

[117] S. Milne, S. Orbell, and P. Sheeran, "Combining motivational and volitional interventions to promote exercise participation: Protection motivation theory and implementation intentions," $\mathrm{Br}$. J. Health Psychol., vol. 7, no. 2, pp. 163-184, 2002.

[118] M. H. Imani-Nasab, H. Seyedin, R. Majdzadeh, B. Yazdizadeh, and M. Salehi, "Development of evidence-based health policy documents in developing countries: a case of Iran," Glob. J. Health Sci., vol. 6, no. 3, pp. 27-36, May 2014.

[119] T. Heart and E. Kalderon, "Older adults: are they ready to adopt health-related ICT?," Int. J. Med. Inf., vol. 82, no. 11, pp. e209-231, Nov. 2013.

[120] G. Leblanc, M.-P. Gagnon, and D. Sanderson, "Determinants of primary care nurses' intention to adopt an electronic health record in their clinical practice," Comput. Inform. Nurs. CIN, vol. 30, no. 9, pp. 496-502, Sep. 2012.

[121] Z. Deng, X. Mo, and S. Liu, "Comparison of the middle-aged and older users' adoption of mobile health services in China," Int. J. Med. Inf., vol. 83, no. 3, pp. 210-224, 2014.

[122] M. G. Morris, V. Venkatesh, and P. L. Ackerman, "Gender and age differences in employee decisions about new technology: An extension to the theory of planned behavior," Eng. Manag. IEEE Trans. On, vol. 52, no. 1, pp. 69-84, 2005.

[123] G. Godin and G. Kok, "The theory of planned behavior: a review of its applications to health-related behaviors," Am. J. Health Promot., vol. 11, no. 2, pp. 87-98, 1996.

[124] H. C. Triandis, "Values, attitudes, and interpersonal behavior.," in Nebraska symposium on motivation, 1979.

[125] A. Karimi-Shahanjarini, A. Rashidian, N. Omidvar, and R. Majdzadeh, "Assessing and Comparing the Short-Term Effects of TPB Only and TPB Plus Implementation Intentions Interventions on Snacking Behavior in Iranian Adolescent Girls: A Cluster Randomized Trial," Am. J. Health Promot., vol. 27, no. 3, pp. 152161, Jan. 2013.

[126] M. Conner and C. J. Armitage, "Extending the Theory of Planned Behavior: A Review and Avenues for Further Research," J. Appl. Soc. Psychol., vol. 28, no. 15, pp. 1429-1464, Aug. 1998.
[127] M. J. Dutta-Bergman, "Theory and practice in health communication campaigns: A critical interrogation," Health Commun., vol. 18, no. 2, pp. 103-122, 2005.

[128] M. Keer, B. van den Putte, and P. Neijens, "The interplay between affect and theory of planned behavior variables," Am. J. Health Behav., vol. 36, no. 1, pp. 107-115, Jan. 2012.

[129] M. S. Hagger, N. Chatzisarantis, S. J. Biddle, and S. Orbell, "Antecedents of children's physical activity intentions and behaviour: Predictive validity and longitudinal effects," Psychol. Health, vol. 16, no. 4, pp. 391-407, 2001

[130] K. Mathieson, "Predicting User Intentions: Comparing the Technology Acceptance Model with the Theory of Planned Behavior," Inf. Syst. Res., vol. 2, no. 3, pp. 173-191, Sep. 1991.

[131] S. Taylor and P. A. Todd, "Understanding Information Technology Usage: A Test of Competing Models," Inf. Syst. Res., vol. 6, no. 2, pp. 144-176, Jun. 1995.

[132] P. A. Pavlou and M. Fygenson, "Understanding and predicting electronic commerce adoption: an extension of the theory of planned behavior," MIS Q., pp. 115-143, 2006.

[133] M. Fishbein, H. C. Triandis, F. H. Kanfer, M. Becker, and S. E. Middlestadt, "Factors influencing behavior and behavior change.," 2001.

[134] K. J. Head and S. M. Noar, "Facilitating progress in health behaviour theory development and modification: the reasoned action approach as a case study," Health Psychol. Rev., vol. 8, no. 1, pp. 34-52, 2014.

[135] C. A. Redding, J. S. Rossi, S. R. Rossi, W. F. Velicer, and J. O. Prochaska, "Health behavior models," in International Electronic Journal of Health Education, 2000.

[136] R. M. Andersen, "Revisiting the behavioral model and access to medical care: does it matter?," J. Health Soc. Behav., pp. 1-10, 1995.

[137] A. Smith-McLallen and M. Fishbein, "Predictors of intentions to perform six cancer-related behaviours: roles for injunctive and descriptive norms," Psychol. Health Med., vol. 13, no. 4, pp. 389401, 2008.

[138] S. M. Noar and R. S. Zimmerman, "Health Behavior Theory and cumulative knowledge regarding health behaviors: are we moving in the right direction?," Health Educ. Res., vol. 20, no. 3, pp. 275-290, 2005.

[139] H.-J. Mosler, "A systematic approach to behavior change interventions for the water and sanitation sector in developing countries: a conceptual model, a review, and a guideline," Int. J. Environ. Health Res., vol. 22, no. 5, pp. 431-449, 2012.

[140] A. Bleakley, J. T. Piotrowski, M. Hennessy, and A. Jordan, "Predictors of parents' intention to limit children's television viewing," J. Public Health Oxf. Engl., vol. 35, no. 4, pp. 525-532, Dec. 2013.

[141] R. J. Pasick, N. J. Burke, J. C. Barker, G. Joseph, J. A. Bird, R. OteroSabogal, N. Tuason, S. L. Stewart, W. Rakowski, M. A. Clark, and others, "Behavioral theory in a diverse society: Like a compass on Mars," Health Educ. Behav., vol. 36, no. 5 suppl, p. 11S-35S, 2009.

[142] D. Albarracin, B. T. Johnson, M. Fishbein, and P. A. Muellerleile, "Theories of reasoned action and planned behavior as models of condom use: a meta-analysis.," Psychol. Bull., vol. 127, no. 1, p. 142, 2001.

[143] T. Webb, J. Joseph, L. Yardley, and S. Michie, "Using the internet to promote health behavior change: a systematic review and metaanalysis of the impact of theoretical basis, use of behavior change techniques, and mode of delivery on efficacy," J. Med. Internet Res., vol. 12, no. 1, p. e4, 2010.

[144] T. L. Webb and P. Sheeran, "Does changing behavioral intentions engender behavior change? A meta-analysis of the experimental evidence.," Psychol. Bull., vol. 132, no. 2, p. 249, 2006.

[145] C. A. Gaither, R. P. Bagozzi, F. J. Ascione, and D. M. Kirking, "A reasoned action approach to physicians' utilization of drug information sources," Pharm. Res., vol. 13, no. 9, pp. 1291-1298, 1996.

[146] I. Ajzen, D. Albarracín, and R. Hornik, Prediction and change of health behavior: Applying the reasoned action approach. Psychology Press, 2012. 
[147] M. Fishbein and I. Ajzen, Predicting and changing behavior: The reasoned action approach. Taylor \& Francis, 2011.

[148] K. Glanz, B. K. Rimer, and K. Viswanath, Health behavior and health education: theory, research, and practice. John Wiley \& Sons, 2008.

[149] S. E. Middlestadt, J. L. Sheats, A. Geshnizjani, M. R. Sullivan, and C. S. Arvin, "Factors associated with participation in work-site wellness programs: implications for increasing willingness among rural service employees," Health Educ. Behav. Off. Publ. Soc. Public Health Educ., vol. 38, no. 5, pp. 502-509, Oct. 2011.

[150] Edward L. Deci, Intrinsic motivation. New York: Plenum Press, 1975.

[151] F. D. Davis, R. P. Bagozzi, and P. R. Warshaw, "Extrinsic and intrinsic motivation to use computers in the workplace1," J. Appl. Soc. Psychol., vol. 22, no. 14, pp. 1111-1132, 1992.

[152] R. J. Vallerand, "Toward a hierarchical model of intrinsic and extrinsic motivation.," 1997.

[153] A. H. Maslow, "A Dynamic Theory of Human Motivation.," 1958.

[154] H. Yamauchi, "An approach to the hierarchical model of motivation in a classroom: a reply to Rousseau and Vallerand," Psychol. Rep., vol. 90, no. 1, pp. 273-278, Feb. 2002.

[155] P. C. Brunel, "Relationship between achievement goal orientations and perceived motivational climate on intrinsic motivation," Scand. J. Med. Sci. Sports, vol. 9, no. 6, pp. 365-374, Dec. 1999.

[156] B. J. Almagro, P. Sáenz-López, and J. A. Moreno, "Prediction of sport adherence through the influence of autonomy-supportive coaching among spanish adolescent athletes," J. Sports Sci. Med., vol. 9, no. 1 , pp. $8-14,2010$.

[157] G. A. Mageau and R. J. Vallerand, "The coach-athlete relationship: a motivational model,” J. Sports Sci., vol. 21, no. 11, pp. 883-904, Nov. 2003.

[158] J. Kowal and M. S. Fortier, "Testing relationships from the hierarchical model of intrinsic and extrinsic motivation using flow as a motivational consequence," Res. Q. Exerc. Sport, vol. 71, no. 2, pp. 171-181, Jun. 2000.

[159] K. R. Wentzel and A. Wigfield, "Academic and Social Motivational Influences on Students' Academic Performance," Educ. Psychol. Rev., vol. 10, no. 2, pp. 155-175, Jun. 1998.

[160] V. Venkatesh and C. Speier, "Creating an effective training environment for enhancing telework," Int. J. Hum.-Comput. Stud., vol. 52, no. 6, pp. 991-1005, 2000.

[161] M. Dacey, A. Baltzell, and L. Zaichkowsky, "Older adults' intrinsic and extrinsic motivation toward physical activity," Am. J. Health Behav., vol. 32, no. 6, pp. 570-582, 2008.

[162] R. L. Oliver, "A cognitive model of the antecedents and consequences of satisfaction decisions," J. Mark. Res., pp. 460-469, 1980.

[163] J. Y. Thong, S.-J. Hong, and K. Y. Tam, "The effects of post-adoption beliefs on the expectation-confirmation model for information technology continuance," Int. J. Hum.-Comput. Stud., vol. 64, no. 9, pp. 799-810, 2006.

[164] T. Verhagen, F. Feldberg, B. van den Hooff, S. Meents, and J. Merikivi, "Understanding users' motivations to engage in virtual worlds: A multipurpose model and empirical testing," Comput. Hum. Behav., vol. 28, no. 2, pp. 484-495, 2012.

[165] F. D. Davis, "A technology acceptance model for empirically testing new end-user information systems: theory and results," Thesis, Massachusetts Institute of Technology, 1985.

[166] D. Kim and H. Chang, "Key functional characteristics in designing and operating health information websites for user satisfaction: An application of the extended technology acceptance model," Int. J. Med. Inf., vol. 76, no. 11, pp. 790-800, 2007.

[167] N. Rahimi and J. Golzarian, "Assessing the Kinect Technology Acceptance/ Diffusion into healthcare (The case of Physical Therapy)," Int. J. Med. Eng. Inform., Accepted for publication.

[168] E. Orruño, M. P. Gagnon, J. Asua, and A. B. Abdeljelil, "Evaluation of teledermatology adoption by health-care professionals using a modified Technology Acceptance Model," J. Telemed. Telecare, vol. 17, no. 6, pp. 303-307, 2011.

[169] V. Venkatesh and M. G. Morris, "Why don't men ever stop to ask for directions? Gender, social influence, and their role in technology acceptance and usage behavior," MIS Q., pp. 115-139, 2000.
[170] F. D. Davis, R. P. Bagozzi, and P. R. Warshaw, "User acceptance of computer technology: a comparison of two theoretical models," Manag. Sci., vol. 35, no. 8, pp. 982-1003, 1989.

[171] R. J. Holden and B.-T. Karsh, "The Technology Acceptance Model: Its past and its future in health care," J. Biomed. Inform., vol. 43, no. 1, pp. 159-172, Feb. 2010.

[172] R. Johnson, "Factors affecting intent to use consumer generic tests: a revised technology acceptance model," 2011.

[173] R. Steele, A. Lo, C. Secombe, and Y. K. Wong, "Elderly persons' perception and acceptance of using wireless sensor networks to assist healthcare," Int. J. Med. Inf., vol. 78, no. 12, pp. 788-801, 2009.

[174] Y. Lee, K. A. Kozar, and K. R. Larsen, "The technology acceptance model: past, present, and future," Commun. Assoc. Inf. Syst., vol. 12, no. 1 , p. 50, 2003.

[175] R. L. Thompson, C. A. Higgins, and J. M. Howell, "Personal computing: toward a conceptual model of utilization," MIS Q., pp. $125-143,1991$.

[176] L. K. Schaper and G. P. Pervan, "ICT and OTs: A model of information and communication technology acceptance and utilisation by occupational therapists," Int. J. Med. Inf., vol. 76, pp. S212-S221, 2007.

[177] M. J. Wills, O. F. El-Gayar, and D. Bennett, "Examining healthcare professionals' acceptance of electronic medical records using UTAUT," Issues Inf. Syst., vol. 9, no. 2, pp. 396-401, 2008.

[178] M. Williams, N. Rana, Y. Dwivedi, and B. Lal, "Is UTAUT really used or just cited for the sake of it? A systematic review of citations of UTAUT's originating article," 2011.

[179] K. Bandyopadhyay and K. A. Fraccastoro, "The effect of culture on user acceptance of information technology," Commun. Assoc. Inf. Syst., vol. 19, no. 1, p. 23, 2007.

[180] H. Sun and P. Zhang, "The role of moderating factors in user technology acceptance," Int. J. Hum.-Comput. Stud., vol. 64, no. 2, pp. 53-78, 2006.

[181] S. Nägle and L. Schmidt, "Computer acceptance of older adults," Work J. Prev. Assess. Rehabil., vol. 41, pp. 3541-3548, 2012.

[182] T. Engebretsen, "Acceptance of information technology by health research projects in low-income countries: Intention to use and acceptance of using EpiHandy (IUAUE)," 2005.

[183] E. M. Rogers, Diffusion of innovations. Simon and Schuster, 2010.

[184] E. M. Rogers, Diffusion of Innovations, 5th Edition, 5th edition. New York: Free Press, 2003.

[185] R. Agarwal and J. Prasad, "The role of innovation characteristics and perceived voluntariness in the acceptance of information technologies," Decis. Sci., vol. 28, no. 3, pp. 557-582, 1997.

[186] M. Cain and R. Mittman, Diffusion of innovation in health care. California Healthcare Foundation Oakland CA, 2002

[187] Y.-H. Lee, Y.-C. Hsieh, and C.-N. Hsu, “Adding Innovation Diffusion Theory to the Technology Acceptance Model: Supporting Employees' Intentions to use E-Learning Systems.," Educ. Technol. Soc., vol. 14, no. 4, pp. 124-137, 2011.

[188] F.-C. Tung, S.-C. Chang, and C.-M. Chou, "An extension of trust and TAM model with IDT in the adoption of the electronic logistics information system in HIS in the medical industry," Int. J. Med. Inf., vol. 77, no. 5, pp. 324-335, 2008.

[189] J. Chen, Y. Park, and G. J. Putzer, "An examination of the components that increase acceptance of smartphones among healthcare professionals," Electron. J. Health Inform., vol. 5, no. 2, p. e16, 2010.

[190] C. W. Clegg, "Sociotechnical principles for system design," Appl. Ergon., vol. 31, no. 5, pp. 463-477, 2000.

[191] B.-T. Karsh, K. H. Escoto, J. W. Beasley, and R. J. Holden, “Toward a theoretical approach to medical error reporting system research and design," Appl. Ergon., vol. 37, no. 3, pp. 283-295, 2006.

[192] C. Keller, "Virtual learning environments in higher education: A study of user acceptance," 2007.

[193] R. G. Fichman, "Information technology diffusion: a review of empirical research," in ICIS, 1992, pp. 195-206.

[194] S.-Y. Hung, C.-Y. Ku, and C.-M. Chang, "Critical factors of WAP services adoption: an empirical study," Electron. Commer. Res. Appl., vol. 2, no. 1, pp. 42-60, 2003. 
[195] M. Y. Yi, J. D. Jackson, J. S. Park, and J. C. Probst, "Understanding information technology acceptance by individual professionals: Toward an integrative view," Inf. Manage., vol. 43, no. 3, pp. 350363,2006

[196] S. Taylor and P. Todd, "Assessing IT usage: The role of prior experience," MIS Q., pp. 561-570, 1995.

[197] V. Venkatesh and F. D. Davis, "A theoretical extension of the technology acceptance model: four longitudinal field studies," Manag. Sci., vol. 46, no. 2, pp. 186-204, 2000.

[198] E. Nkenke, E. Vairaktaris, A. Bauersachs, S. Eitner, A. Budach, C. Knipfer, and F. Stelzle, "Acceptance of virtual dental implant planning software in an undergraduate curriculum: a pilot study," BMC Med. Educ., vol. 12, no. 1, p. 90, 2012.

[199] W. G. Chismar and S. Wiley-Patton, "Test of the technology acceptance model for the internet in pediatrics.," in Proceedings of the AMIA Symposium, 2002, p. 155.

[200] J.-H. Wu and S.-C. Wang, "What drives mobile commerce?: An empirical evaluation of the revised technology acceptance model," Inf. Manage., vol. 42, no. 5, pp. 719-729, 2005.

[201] P. Legris, J. Ingham, and P. Collerette, "Why do people use information technology? A critical review of the technology acceptance model," Inf. Manage., vol. 40, no. 3, pp. 191-204, 2003.

[202] H.-H. Chen and S.-C. Chen, "The empirical study of automotive telematics acceptance in Taiwan: comparing three Technology Acceptance Models," Int. J. Mob. Commun., vol. 7, no. 1, pp. 50-65, 2009.

[203] V., Michael G.Davis, Gordon B.Davis, Fred D. Venkatesh, "User Acceptance of Information Technology: Toward a Unified View," MIS Q., vol. 27, no. 3, pp. 425-478, Sep. 2003.

[204] Y. K. Dwivedi, M. D. Williams, and B. Lal, "The diffusion of research on the adoption and diffusion of information technology," in Open IT-Based Innovation: Moving Towards Cooperative IT Transfer and Knowledge Diffusion, Springer, 2008, pp. 3-22.

[205] M. D. Williams, Y. K. Dwivedi, B. Lal, and A. Schwarz, "Contemporary trends and issues in IT adoption and diffusion research," J. Inf. Technol., vol. 24, no. 1, pp. 1-10, 2009.

[206] M. D. Williams, N. P. Rana, and Y. K. Dwivedi, "A bibliometric analysis of articles citing the unified theory of acceptance and use of technology," in Information Systems Theory, Springer, 2012, pp. 3762 .

[207] B. Kijsanayotin, S. Pannarunothai, and S. M. Speedie, "Factors influencing health information technology adoption in Thailand's community health centers: Applying the UTAUT model," Int. J. Med. Inf., vol. 78, no. 6, pp. 404-416, 2009.

[208] V. P. Aggelidis and P. D. Chatzoglou, "Using a modified technology acceptance model in hospitals," Int. J. Med. Inf., vol. 78, no. 2, pp. 115-126, 2009.

[209] X. Luo, H. Li, J. Zhang, and J. P. Shim, "Examining multidimensional trust and multi-faceted risk in initial acceptance of emerging technologies: An empirical study of mobile banking services,” Decis. Support Syst., vol. 49, no. 2, pp. 222-234, 2010.

[210] L. Carter and V. Weerakkody, "E-government adoption: A cultural comparison," Inf. Syst. Front., vol. 10, no. 4, pp. 473-482, 2008.

[211] P. Duyck, B. Pynoo, P. Devolder, T. Voet, L. Adang, and J. Vercruysse, "User acceptance of a picture archiving and communication system. Applying the unified theory of acceptance and use of technology in a radiological setting.," Methods Inf. Med., vol. 47, no. 2, pp. 149-156, 2007.

[212] O. Alikilic and U. Atabek, "Social media adoption among Turkish public relations professionals: A survey of practitioners," Public Relat. Rev., vol. 38, no. 1, pp. 56-63, 2012.

[213] L. Curtis, C. Edwards, K. L. Fraser, S. Gudelsky, J. Holmquist, K. Thornton, and K. D. Sweetser, "Adoption of social media for public relations by nonprofit organizations," Public Relat. Rev., vol. 36, no. 1, pp. 90-92, 2010.

[214] P. Robson and K. E. Sutherland, "Public relations practitioners and social media: themes in a global context," in WORLD PUBLIC RELATIONS FORUM 2012, 2012, p. 103.

[215] A. P. Balogh, K. V. Siakas, S. Koinig, D. Ekert, D. Coakley, R. Colomo-Palacios, and V. Kostoglou, "Social Media Networker: A New Profile for a New Market," in Electronic Business and Marketing, Springer, 2013, pp. 137-146.

[216] M. A. McClellan, "Clinician Acceptance of Electronic Medical Records (EMRs): Relating Personality Factors to Continuance Intention," UNIVERSITY OF MINNESOTA, 2011.

[217] Y. K. Dwivedi, N. P. Rana, H. Chen, and M. D. Williams, "A Metaanalysis of the Unified Theory of Acceptance and Use of Technology (UTAUT)," in Governance and Sustainability in Information Systems. Managing the Transfer and Diffusion of IT, Springer, 2011, pp. 155170.

[218] E. AbuShanab, J. M. Pearson, and A. J. Setterstrom, "Internet banking and customers' acceptance in Jordan: the unified model's perspective," Commun. Assoc. Inf. Syst., vol. 26, no. 1, p. 23, 2010.

[219] P. Duyck, B. Pynoo, P. Devolder, T. Voet, L. Adang, D. Ovaere, and J. Vercruysse, "Monitoring the PACS implementation process in a large university hospital - discrepancies between radiologists and physicians," J. Digit. Imaging, vol. 23, no. 1, pp. 73-80, 2010.

[220] H. C. Lucas Jr, E. B. Swanson, and R. Zmud, "Implementation, innovation, and related themes over the years in information systems research," J. Assoc. Inf. Syst., vol. 8, no. 4, p. 8, 2008.

[221] L. Silva, "Post-positivist Review of Technology Acceptance Model.," J. Assoc. Inf. Syst., vol. 8, no. 4, p. 11, 2007.

[222] J. Ogden, "Some problems with social cognition models: a pragmatic and conceptual analysis.," Health Psychol., vol. 22, no. 4, p. 424, 2003.

[223] E. M. Van Raaij and J. J. Schepers, "The acceptance and use of a virtual learning environment in China," Comput. Educ., vol. 50, no. 3, pp. 838-852, 2008.

[224] D. Albarracín, J. C. Gillette, A. N. Earl, L. R. Glasman, M. R. Durantini, and M.-H. Ho, "A Test of Major Assumptions About Behavior Change: A Comprehensive Look at the Effects of Passive and Active HIV-Prevention Interventions Since the Beginning of the Epidemic.," Psychol. Bull., vol. 131, no. 6, pp. 856-897, 2005.

[225] P. Sheeran, C. Abraham, and S. Orbell, "Psychosocial correlates of heterosexual condom use: a meta-analysis.," Psychol. Bull., vol. 125, no. 1, p. $90,1999$.

[226] R. P. Bagozzi, "The Legacy of the Technology Acceptance Model and a Proposal for a Paradigm Shift.," J. Assoc. Inf. Syst., vol. 8, no. 4, p. 3, Apr. 2007.

[227] J. E. Painter, C. P. Borba, M. Hynes, D. Mays, and K. Glanz, "The use of theory in health behavior research from 2000 to 2005: a systematic review," Ann. Behav. Med., vol. 35, no. 3, pp. 358-362, 2008.

[228] A. J. Rothman, “'Is there nothing more practical than a good theory?': Why innovations and advances in health behavior change will arise if interventions are used to test and refine theory," Int. J. Behav. Nutr. Phys. Act., vol. 1, no. 1, p. 11, Jul. 2004.

[229] V. Weerakkody, Y. K. Dwivedi, and Z. Irani, "The diffusion and use of institutional theory: a cross-disciplinary longitudinal literature survey," J. Inf. Technol., vol. 24, no. 4, pp. 354-368, Sep. 2009.

[230] R. Crosby and S. M. Noar, "Theory development in health promotion: are we there yet?," J. Behav. Med., vol. 33, no. 4, pp. 259-263, 2010.

[231] N. Rahimi and M. Ibarra, "A Review of Multiple User Center Design Methods for New Product Development in Smart and Connected Health Applications," in 2014 Proceedings of PICMET'14, 2014, pp. 3498-3510. 